\title{
LA CUESTIÓN DE LA RESPONSABILIDAD PENAL DE LAS PERSONAS JURÍDICAS. UN PUNTO Y SEGUIDO
}

\author{
Laura Zúñiga Rodríguez ${ }^{1}$
}

SUMARIO: I.- Planteamiento. II.- Características de la nueva criminalidad y los retos que plantea al sistema penal. 1. La empresa como organización generadora de riesgos. 2. La persona jurídica como construcción jurídica que dificulta establecer la responsabilidad individual. 3. La persona jurídica como construcción jurídica que dificulta establecer la responsabilidad individual. 4. Principales consecuencias en el ámbito penal de la existencia de esta nueva criminalidad. 4.1. Acentuación de los fines preventivos del Derecho Penal. 4.2. Preponderancia de bienes jurídicos colectivos, 4.3. Superación del problema causal. 4.4. Dificultades para determinar a las víctimas y los resultados lesivos. III.- Los modelos de responsabilidad individual: la deconstrucción. 1. El modelo de la responsabilidad de los órganos y representantes. 2. El modelo de responsabilidad del titular de la empresa. IV. - La responsabilidad penal de la propia persona jurídica. Principales problemas. 1. La responsabilidad de las personas jurídicas en el sistema sancionador administrativo. 2. Las consecuencias accesorias. 3. La construcción dentro del propio Derecho Penal o un modelo paralelo. 4. Problemas de injusto y culpabilidad del modelo. V.-Conclusiones: De la deconstrucción a la construcción de un modelo de responsabilidad penal a la persona jurídica.

RESUMEN: La autora en este trabajo nos presenta una revisión del principio societas delinquere non potest a partir del auge de una criminalidad organizada, estableciendo una vinculación entre criminalidad de empresa y criminalidad organizada al encontrar como núcleo de interrelación a la empresa. A la luz de los escándalos financieros de los últimos tiempos, se verifica el problema de la individualización de responsabilidades reconociendo serias lagunas de punibilidad, especialmente a partir del cuestionamiento de los modelos de responsabilidad individual. Por ello propone la construcción de un modelo de responsabilidad penal de la persona jurídica paralelo a la responsabilidad individual como modo de hacer frente con eficacia a la macrocriminalidad que demuestra su extraordinario poder criminógeno, sin soslayar garantías básicas de un Estado de Derecho.

1 Profesora Titular, Universidad de Salamanca. 


\section{Palabras clave: Criminalidad - Empresa - Criminalidad organizada - Responsabilidad - Órganos - Representantes.}

\section{PLANTEAMIENTO}

El asunto de la responsabilidad penal de las personas jurídicas se está convirtiendo en el Derecho Penal en lo que Merton -en ciencias socialesllamaría un strategic research site, porque cruza diagonalmente todos los temas de la teoría del delito y plantea necesariamente la revisión de sus presupuestos, esto es, la actualidad de los principios limitadores del ius puniendi ${ }^{2}$, las vinculaciones entre injusto penal e injusto administrativo ${ }^{3}$, las relaciones del Derecho Penal con otras ramas del ordenamiento jurídico,

2 La tensión entre las demandas de eficacia y los principios limitadores del poder punitivo del Estado es uno de las cuestiones actuales más debatidas en el Derecho Penal al hilo del auge de la nueva criminalidad propia de un mundo globalizado. Cfr. SILVA SÁNCHEZ, La expansión del Derecho Penal. Aspectos de la Política Criminal en las sociedades postindustrializadas, Madrid, Civitas, 2001, 2a edición, p. 83: “...la exigencia de dar respuesta a la globalización y a su delincuencia se concibe, en general, en términos punitivistas, esto es, de evitación de hipotéticas lagunas, así como de rearme jurídico penal frente a modelos de delincuencia que crean una fuerte sensación de inseguridad no solo a los individuos, sino también -y de modo especial- a los propios Estados". Vid. más ampliamente ZÚÑIGA Rodríguez, Politica Criminal, Madrid, Colex, 2001, pp. 271-277.

3 No se puede en el poco espacio de un artículo zanjar esta cuestión, pero al ser un tema crucial para el debate de la responsabilidad penal de las personas jurídicas, es necesario sentar los términos del mismo y dejar clara la postura personal, en tanto presupuesto de la discusión. Los esfuerzos desde Goldschmidt por encontrar un criterio diferenciador entre injusto penal e injusto administrativo han sido prácticamente vanos. Así es dominante la consideración de que no existe una diferencia ontológica entre ambas infracciones; prueba de ello son delitos que se convierten en infracciones administrativas y viceversa, como las infracciones tributarias. En la doctrina administrativista Vid.: GARCíA DE Enterría, Curso de Derecho Administrativo, Madrid, Civitas, 1984, T. II, $2^{3}$ edición, pp. 147 y ss, PARADA VÁsQUez, "Las sanciones administrativas", en AA. VV., La empresa en la CE, Madrid, Ed. Aranzadi, 1989, p. 542. SUAY RINCÓN, Sanciones Administrativas, Bolonia, Publicaciones del Real Colegio de España, p. 34. "Nada hay, ontológicamente distinto entre unas sanciones y otras. Su sustancia es la misma y por consiguiente, nada justifica que los principios, que constituyen expresión de esa sustancia, sean diferentes en uno y orro caso" (el subrayado es mío). En el ámbito penal: Vid. específicamente: MARTínez PÉrez, "La inflación del Derecho Penal y del Derecho Administrativo", en EPC, $\mathrm{N}^{\mathrm{a}}$ VI, 1983, p. 205. GARCÍA ARÁN, "Remisiones normativas, leyes penales en blanco y estructura de la norma penal", en EPC, $\mathrm{N}^{\circ}$ XVI, 1993, p. 101. PolaINo NAvarrete, "Derecho Penal criminal y Derecho administrativo sancionador", en RCLM, N 7, 1989, p. 77 3. Por el traspaso de todas las garantías penales al ordenamiento administrativo sancionador se pronuncian todos los autores que consideran que no existe una diferencia sustancial entre ambos injustos Vid. por todos Cerezo Mir, Curso de Derecha Penal Español, Introducción I, Madrid, Tecnos, 1996, p. 45. En contra, aduciendo un menor nivel de garantías en el ordenamiento administrativo. Vid. Cid MOLINÉ, "Garantías y sanciones (Argumentos contra la tesis de la identidad de garantías entre las sanciones punitivas)", p. 141 y Silva SÁnchez, (n. 2) p. 125, para quien "...lo decisivo de la referida diferenciación no es (solo) la configuración del injusto, sino los criterios desde que se contempla, los criterios de imputación de ese injusto y las garantías de diverso signo (formales y 
la tendencia actual expansiva de la intervención penal ${ }^{4}$, la legitimidad del recurso penal para los nuevos delitos socioeconómicos, entre otros. Además, afecta a dos de los temas actuales de la Política Criminal moderna: la criminalidad organizada y el terrorismo, puesto que en el núcleo de ambos tipos de delincuencia está la persona jurídica y las organizaciones. De ahí que abordar esta cuestión de una manera seria y no tangencial requiera irremediablemente ahondar en los presupuestos y seguramente escape de sus soluciones simplistas como las manidas "posiciones a favor" versus "posiciones en contra". Seguramente, también, aquí esté el "talón de Aquiles" de esta cuestión: la imposibilidad para llegar a consensos sobre las cuestiones fundamentales del Derecho Penal, de las que se ha discutido a lo largo de todo el desarrollo de esta disciplina, que pueden sintetizarse en el problema de la responsabilidad penal.

Tampoco considero que la metodología propia para abordar este tema sea la de plantear la confrontación entre argumentos político-criminales de eficacia frente a imposibilidades de orden dogmático ${ }^{5}$. Hoy en día las soluciones dogmáticas pasan necesariamente por dar cabida a problemas de orden político-criminal, desde Roxin. Y por lo menos este es un primer punto de acuerdo que no merece la pena remover.

Encontrar el hilo de la madeja en esta cuestión no es nada fácil si se quiere analizar un tema en el que la visión del penalista está sesgada para abordar el objeto de la criminalidad de grupo, dado que el principio de la responsabilidad personal (léase persona individual) constituye el pilar en el cual se asienta toda la estructura de la teoría del delito. Por tanto,

materiales) que rodean la imposición de sanción al mismo. A este respecto es evidente que el sometimiento a un juez es una diferencia cualitativa, como lo es la imposibilidad de la Administración imponga sanciones privativas de libertad". Personalmente creo que no se puede sostener que entre ambos hay solo una diferencia de grado, siguiendo a ANTÓN ONECA, Derecho Penal, anotado y corregido por J. Hernández y B. Merino, Madrid, Akal, $1986,2^{\text {a }}$ edición, p. 22; o Torío, "Injusto penal e injusto administrativo (presupuestos para la reforma del sistema penal)", en Estudios sobre la CE en Homenaje a Garcia de Enterría, Madrid, Civitas, 1991, T III, pp. 2538-2539. En todo caso, el traspase de los principios penales al sistema sancionador administrativo es una necesidad político-criminal (principio de intervención mínima) si se quiete limitar la potestad punitiva del Estado en general; aunque habrá que reflexionar por especies de delitos. Vid. más ampliamente, ZÚNiga RodrfgueZ, "Relaciones entre Derecho Penal y Derecho administrativo sancionador ¿Hacia una 'administrativización del Derecho Penal o una 'penalización' del Derecho administrativo sancionador?, en AA. VV., Homenaje al Dr. Marino Barbero Santos, In memoriam, Cuenca, Ediciones de la Universidad de Castilla- La Mancha / Universidad de Salamanca, 2001, pp. 1430 y ss. Criminal en las sociedades postindustrializadas, ob. cit, passim.

5. Respecto a este supuesto debate entre eficacia (vertiente político-criminal) y principios (vertiente dogmática), vale la pena aclarar que en ningún caso se ha propuesto la admisión de la responsabilidad penal de las personas jurídicas por imposibilidades probatorias de la responsabilidad individual. Más bien, consideramos que las dificultades probatorias provienen de los inconvenientes de la dogmática desarrollada desde la responsabilidad individual para solucionar los problemas de delincuencia cometida por grupos organizados. 
un primer paso que hemos dado quienes nos hemos aproximado al tema es el de deconstruir este andamiaje teórico intentado comprobar la validez del mismo, poniendo a prueba los modelos de resolución de responsabilidad individual frente a estas nuevas formas de criminalidad organizada, empresarial, transnacional, en la que los sujetos colectivos constituyen una pieza clave. De ahí que la metodología utilizada en esta ocasión sea la de, en una primera parte, deconstruir el modelo de responsabilidad personal y, una segunda parte, en la que se proponga un modelo de construcción o de solución.

Una dificultad más antes de abordar la cuestión. La teoría que tiende a la abstracción y a la generalización se encuentra con una práctica plagada de importantes diferenciaciones. La abstracción persona jurídica ${ }^{6}$ no comprende las mismas agrupaciones de personas en los mismos países, ni se refiere a todas las organizaciones con potencial poder criminógeno. Es una construcción jurídica ${ }^{7}$ que depende de cada legislación y no comprende, las asociaciones de hecho. De ahí que sea conveniente señalar previamente a qué sujetos colectivos nos estamos refiriendo al encuadrar el tema. En términos económicos -funcional a los delitos socioeconómicos- la definición que prima es empresa, en tanto unidad económica del mercado constituida para producir bienes y servicios ${ }^{8}$. Pero también hay asociaciones de personas que no tienen fines de lucro como las empresas, que también pueden ser agentes criminógenos, como puede ser un partido político, o una simple asociación sin fines lucrativos, por lo que conviene ampliar el espectro conceptual a los delitos que se cometen en

6 Utilicemos la definición de De Castro y BRAvo, Persona jurídica, p. 268: La persona jurídica consiste en "un grupo de personas (tipo asociación) o en una organización (tipo fundación), que constituyen unidades cerradas herméricamente, con propia e inviolable zona íntima; $y$, siempre como la persona física, con la capacidad de sujeto de derechos y obligaciones, participando como tal en el tráfico jurídico por medio de sus órganos".

La teoría general del Derecho sobre la persona jurídica considera que esta es sujeto del Derecho en general. Los estudios modernos prescinden de la discusión sobre su naturaleza ficticia, real o supraindividual. Como dice SANTIAGO NINO, Introducción al análisis del Derecho, Barcelona, Ariel, 1991, 4a edición, pp. 232 y ss., el enfoque correcto consiste en centrar el análisis en las funciones que la expresión "persona jurídica" cumple en los distintos contextos. En suma, la noción "persona jurídica" es una muestra del poder de sintesis de una complejidad de enunciados que describen conductas de ciertos individuos y tienen en cuenta una serie de normas jurídicas.

Este es el concepto que ha servido de elemento aglutinador para los delitos considerados "criminalidad de empresa", a partir del famoso libro de SHÜNEMANN, Unternebmenskriminalität und Strafrecht, Köln- Berlin-Bonn/München, Carl Herymanns Verlag, 1979. Asimismo, Vid. SHÜNEMANN, "Cuestiones básicas de dogmática jurídico-penal y de política criminal acerca de la criminalidad de empresa", en ADPCP, 1988, p. 531: "Delitos económicos en los que por medio de una actuación para una empresa se lesionan bienes jurídicos e intereses externos, incluidos los bienes jurídicos e intereses propios de los colaboradores de la empresa". Indudablemente nos estaríamos refiriendo al concepto amplio de delitos socioeconómicos (que acoge el $\mathrm{CP}$, dicho sea de paso), incluyendo delitos patrimoniales como la estafa y los delitos contra el medio ambiente. 
una organización ${ }^{9}$ de personas, al margen de su personería jurídica ${ }^{10}$. En suma, si buscamos un denominador común en este tipo de criminalidad es sin duda la organización ${ }^{11}$.

No es conveniente adentrarse en el debate teórico sin tener como horizonte dos hechos de la vida real que han influenciado la Política Criminal internacional y nacional centrándola en el terrorismo y la criminalidad organizada, que son: los atentados del 11 de septiembre de 2001 y las resoluciones de la Audiencia Nacional de agosto y octubre de 2002 en las se ha resuelto suspender las actividades de la asociación política Batasuna. En ambos casos el denominador común es la comisión de delitos por parte de organizaciones férreamente estructuradas en las que la utilización de empresas (personas jurídicas), asociaciones y organizaciones al margen del Derecho, se entrecruzan en un conglomerado económico y criminal difícil de deslindar. Pero hay que tener en cuenta otro hecho que muestra la impunidad de las organizaciones empresariales. El hundimiento del buque petrolero Prestige en noviembre de 2002, en las costas de Galicia, donde la dificultad para detectar el patrimonio de la empresa que debe responder por los daños ocasionados es ingente, porque se trata "banderas de conveniencia", es decir, empresas que fletan barcos y cuyo domicilio está en paraísos fiscales ${ }^{12}$, en las que la determinación de los reales propietarios se asemeja a las famosas muñecas rusas. El único que ha respondido en este momento es el Capitán, a quien se le detuvo y se le impuso una fianza de tres millones de euros.

Previamente a analizar el proceso de deconstrucción y construcción de las respuestas penales a propósito de la nueva criminalidad organizada

9 La teoría de las organizaciones, enseña que una organización, además de estar encaminadas hacia fines u objetivos específicos, estructura diferenciada horizontal y vertical, sistema de roles individualmente asignados, lo que le da entidad propia es la racionalidad, la manera como la organización define su objetivo. Cfr. MAYNTz, Sociología de la organización, Madrid, Alianza Universidad, 1990, $5^{\mathrm{a}}$ reimpresión, p. 26.

10. En este punto, modifico mi punto de vista sostenido en Zúñiga RodrígueZ, Bases para un modelo de imputación de responsabilidad penal a las personas jurídicas, Pamplona, Aranzadi, $2003,2^{a}$ edición, p. 49, en donde digo que para establecer como sujeto de impuración a la agrupación tiene que tener personería jurídica. Mi estudio más profundo sobre las organizaciones me hacen sostener que se trata de formaciones sociales con entidad propia al margen de la personería jurídica. Cfr. MAYNTZ, Sociología de la urganización, ob. cit,, p. 80: "Las organizaciones fuera del ordenamiento jurídico se encuentran amenazadas constantemente por sanciones estatales. El mantenimiento en la clandestinidad es para ellas el principio dominante; amoldarse constantemente a acontecimientos imprevistos".

11 La concepción de la organización como sistema social es dominante hoy en la teoría de las organizaciones. Se trata de una formación social continente de diversos subsistemas (grupos, individuos, etc.) y contenido a su vez en sistemas más amplios (Comunidad, Sociedad, etc.). Cfr. MOUZELIS, Organización y burocracia. Un análisis de las teorias modernas sobre organizaciones sociales, Barcelona, Ediciones Península, 1991, $3^{\text {a }}$ edición, p. 185.

12 Vid. El PAís, 8 de noviembre de 2002, p. 28: "Ni la compañía Crown Resources, la petrolera que fletó el el Prestige, ni Alpha Group, el consorcio ruso para el que trabajaba el buque, esrán dispuestos a asumir responsabilidad alguna". 
-lo que tradicionalmente se conoce como la cuestión de la responsabilidad penal de las personas jurídicas-, resulta conveniente estudiar un aspecto que sirve de base a este debate: las características de esta nueva criminalidad que plantean nuevos retos al sistema penal.

\section{CARACTERÍsticas DE LA NUEVA CRIMINALIDAD Y LOS RETOS QUE PLANTEA AL SISTEMA PENAL}

Cada sociedad produce su propia criminalidad o, dicho de otro modo, la criminalidad es reflejo de las relaciones sociales. Los rasgos de la criminalidad actual están condicionados fundamentalmente por el espectacular desarrollo tecnológico de los últimos tiempos, especialmente centrado en el área de las telecomunicaciones y la información. La rapidez con que se pueden mover las personas, las ideas, las cosas, el dinero, en un mundo donde ha primado la ideología del libre mercado, ha generado la posibilidad de lucrar ilícitamente de manera mucho más fácil y efectiva. La criminalidad organizada con sus enormes ganancias ilícitas progresa a pasos agigantados utilizando la corrupción económica y la corrupción política, en la cual el eje de la misma la constituye la gran empresa.

La capacidad real de dominio en el mercado y en el poder político de las grandes empresas, en momentos históricos en los que existen empresas multinacionales que poseen un volumen de negocios superior al de muchos Estados ${ }^{13}$, es un hecho incontrastable y que jurídicamente plantea problemas no solo de orden económico, sino también de tipo político ${ }^{14}$. Dicha capacidad real de las grandes empresas, las centra como eje de la criminalidad empresarial y la criminalidad organizada dentro del mercado internacional de nuestros días. Se estima que la criminalidad económica ligada al mundo financiero y a la gran banca, recicla sumas de dinero superiores al billón de euros por año, esto es, más que el producto nacional bruto (PNB) de un tercio de la humanidad ${ }^{15}$. Sostener que las personas jurídicas no pueden ser sujetos directos de imputación penal significa realmente dejar fuera del alcance de sanciones graves a los sujetos económicos y políticos más importantes de nuestra era.

13 Cfr. RAmonet, Guerras del siglo XXI. Nuevos miedos, nuevas amenazas, traducción de J. A. Soriano, Barcelona, Mondadori, 2002, p. 20: "El volumen de negocios de General Motors es superior al PIB de Dinamarca; el de Exxon Mobil excede al PIB de Austria. Cada una de las cien empresa globales más importantes del mundo vende más de lo que exporta cualquiera de los ciento veinte países más pobres. Estas macroempresas controlan el $70 \%$ del comercio mundial".

14 La soberanía de los Estados nacionales ya tocada por el nacimiento de uniones de países que desplazan su centro de decisiones a instituciones ajenas a sus propias fronteras, necesariamente tiene que verse resentida ante el poder económico de estas grandes empresas.

RAMONET, Guerras del Siglo XXI. Nuevas guerras, nuevas amenazas, ob. cic., p. 14. 
Otro vector importante para entender esta nueva criminalidad es el propio dinamismo que ha generado la tecnología como objetivización de la obra del hombre y cuyas leyes no se pueden explicar con las tradicionales teorías causales. Se habla de "Sociedad del riesgo", "Derecho Penal del riesgo", "epistemología del riesgo", pero todas ellas denotan esa angustia vital del hombre moderno por pretender dominar la naturaleza, cuando esta ya ha tomado vida propia y se rige por reglas independientes de la voluntad humana. En el plano criminológico esto supone que la unión entre tecnología y energía humana en manos de grandes organizaciones criminales aumenta de forma exponencial su capacidad criminógena. Es la llamada macrocriminalidad, puesta de manifiesto en los atentados del 11 de septiembre de 2001, cuyo tratamiento por parte de los poderes públicos está desbordando las reglas de imputación penal, para ser abordadas como "nuevas guerras"16. En el plano jurídico-penal, esto significa que dada la cantidad de conductas riesgosas para bienes jurídicos importantes en la sociedad y dado que en la lesión de los mismos intervienen muchos otros factores imponderables ("lo desconocido"), el Derecho Penal no puede esperar a que se produzca la lesión de los mismos y centra su núcleo de imputación en la prevención de las conductas riesgosas para los bienes jurídicos, en la contención del riesgo. No cabe duda que, entonces, que si se trata de contener los riesgos, es fundamental observar qué sujetos son los principales agentes criminógenos.

\section{La empresa como organización generadora de riesgos.}

La realidad social se percibe y estructura como una constante tensión entre seguridad y riesgo, en la que el pragmatismo del consumo y el progreso justifican ciertos peligros para bienes jurídicos. Se trata de riesgos colectivos, riesgos de masas que se admiten por los beneficios que reportan, pero la sociedad se ve en la necesidad de limitarlos, acotarlos para que no se desborden y no produzcan lesiones a bienes jurídicos.

El principal agente de riesgos para los bienes jurídicos colectivos de nuestros días es la empresa. Los delitos contra el medio ambiente, contra los trabajadores, contra la salud pública (responsabilidad por el producto), fraudes contables, etc., se cometen principalmente en el seno de empresas. No solo dentro del comercio legal, sino también dentro de los tráficos ilícitos encontramos que en la mayoría de los casos existen em-

\footnotetext{
16. Según KAldor, Las nuevas guerras. La violencia organizada en la era global, traducción de M.L. Rodríguez Tapia, Barcelona, Tusquets, 1991, p. 16: "las nuevas guerras implican un desdibujamiento de las distinciones entre guerra (normalmente definida como la violencia por morivos políticos entre Estados o grupos políticos organizados), crimen organizado (la violencia por motivos particulares, en general el beneficio económico, ejercida por grupos organizados privados) y violaciones a gran escala de los derechos humanos (la violencia contra personas individuales ejercida por Estados o grupos organizados políticamente).
} 
presas (reales, fantasmas, interpuestas, en cadena, etc.) que intervienen facilitando la impunidad de los hechos por el camuflaje dentro de la estructura de una persona jurídica.

En las sociedades postindustrializadas la trascendencia social y criminológica de la criminalidad de empresa desplaza en importancia a la llamada "criminalidad clásica", aunque en muchos casos permanezca en las cifras negras ${ }^{17}$ y la persecusión penal aún sea muy deficitaria. Factores sociales también favorecen este déficit de penalidad, como el hecho de tratarse de una criminalidad cometida por sujetos de alto standing social, muy bien valorados socialmente (collar white crime), quienes están bien relacionados con el poder económico y político ${ }^{18}$.

En todo caso, la empresa se manifiesta como una importante fuente de riesgo para bienes jurídicos fundamentales como la vida, la salud, riesgos que se desarrollan en tres momentos:

a) En el propio proceso de producción: es el caso de los accidentes laborales. El trabajador al estar en contacto con la máquina y realizar actividades peligrosas en el desenvolvimiento de sus labores, pone en riesgo su vida y su salud.

b) Con los bienes producidos por la actividad industrial. La producción masiva de productos y alimentos en grandes escalas, su comercialización por grandes cadenas dificultan la determinación de los procesos causales que intervienen desde que el producto empieza a elaborarse hasta que llega al consumidor. De ahí la complejidad de la determinación de la responsabilidad por los productos defectuosos.

c) Con los desechos industriales. Los desechos de la actividad industrial pueden ser generadores de riesgos constitutivos de delitos. La emisión de humos, emisión de gases tóxicos, productos radiactivos, etc. Muchos de ellos podrían producir delitos contra el medio ambiente, contra el Patrimonio Artístico, urbanísticos, etc.

La moderna empresa ha protagonizado en los últimos decenios cambios importantes, en un proceso de concentración de capitales (fusiones, absorciones, etc.), para ser más competitiva en un mercado liberal sumamente exigente, donde la misma tiene que ofrecer el mejor producto al menor coste para el consumidor.

17 Los espectaculares escándalos financieros en el corazón del capitalismo, Estados Unidos, parecen mostrar solo la punta de un iceberg en el que actividades lícitas e ilícitas se entrecruzan.

18 Las dificultades que está teniendo la jurisprudencia italiana para sancionar delitos en el que está involucrado su Primer Ministro Berlusconi, es una exacerbación de las vinculaciones entre poder económico y poder político. 
Se puede afirmar que una de las características más destacables del capitalismo de este fin de siglo, es la concentración de grandes capitales con las fusiones y absorciones de empresas, produciéndose grandes sociedades complejas que operan en distintos países: los "grupos de empresas", "complejos empresariales o de compañías", "holdings" o "conglomerados económicos", que pueden desarrollarse en distintos países, donde la distribución del proceso de producción, distribución y comercialización se realiza con diferentes empresas, habiendo normalmente una "madre" y "filiales", aunque cada una mantiene su personería jurídica propia. La funcionalidad de estas "asociaciones de asociaciones", está precisamente en la optimización de recursos, reduciendo costos y repartiendo riesgos y responsabilidades ${ }^{19}$.

Esta complejidad se hace aún más evidente cuando hablamos de la moderna empresa en la sociedad de la información y en el mercado globalizado, donde la organización de la misma ya no es vertical-jerárquica como tradicionalmente lo ha sido, sino que se organiza en redes multidireccionales, la mayoría de las veces vinculadas a una gran empresa, donde las estructuras son altamente descentralizadas y muy flexibles de acuerdo a la flexibilidad de los mercados ${ }^{20}$. Siguiendo la definición de Castells ${ }^{21}$ : "La 'empresa horizontal' es una red dinámica y estratégicamente concebida de unidades autoprogramadas y autodirigidas basadas en la descentralización, la participación y la coordinación". Es decir, el modelo organizativo propiciado por el cambio tecnológico y las nuevas necesidades de un mercado muy competitivo y cambiante, donde los riesgos se diversifican en la red, ya no se define como un conjunto de medios orientados a unos fines comunes, sino que la empresa-red está constituida por un sistema de redes interconectados, pero a la vez autónomos en sus fines. En una red-horizontal, flexible, autónomamente regulada, con fines propios, pero vinculados a una gran empresa, difícilmente se puede establecer el núcleo de decisión de los comportamientos ilícitos.

\section{La persona jurídica como construcción jurídica que dificulta establecer la responsabilidad individual}

El progreso de las personas jurídicas sobre todo de las sociedades anónimas y sociedades de responsabilidad limitada, se concibió a partir de la diversificación entre riesgo y responsabilidad. Los miembros de las sociedades limitan su riesgo (llámese patrimonio y demás bienes jurídi-

\footnotetext{
19 Cfr. Terradillos, "Delitos societarios y grupos de empresas", en BaYlos / Collado (eds.), Grupos de Empresas y Derecho del Trabajo, Madrid, Trotta, 1994, p. 74.

20 Cfr. Castells, 2001, pp. 201-254.

$21 \quad 2001$, pp. 216-217.
} 
$\cos )$, con la determinación de la responsabilidad en la propia persona jurídica. Las personas jurídicas siempre necesitan de personas físicas para $a_{c t u a r}{ }^{22}$. Se produce así, naturalmente, un problema de escisión entre quienes actúan y quienes se responsabilizan del hecho ${ }^{23}$. Ello significa que siempre, en toda actuación de la personas jurídica, existe una disociación entre actuación y sujeto jurídico imputable. Con lo cual se observa claramente que se trata de una imputación ${ }^{24}$ : son unos los que actúan (los directivos, los órganos, los representantes) y otro el que responde, es decir, el que asume la responsabilidad de tal actuación, la persona jurídica.

Aquí se plantea un problema importante. La disociación entre las personas que actúan y el sujeto jurídico de imputación que caracteriza la persona jurídica, que se resuelve en el Derecho civil, mercantil y tributario con la teoría de la representación según la cual, las actuaciones que realiza su representante vinculan a la persona jurídica como sujeto de responsabilidad. Sin, embargo en el Derecho Penal, por el principio de la responsabilidad personal y el principio de dolo o culpa, el representante solo responderá si él personalmente realiza el delito con conciencia y voluntad o con negligencia, como se analizará pronto.

El conjunto de características reseñadas de la actuación en organizaciones de tipo empresarial, denota comportamientos complejos en los

22 Esta es una evidencia que ha servido para que los detractores de la responsabilidad penal de las personas jurídicas pretendan fundamentar la necesidad de individualizar siempre la responsabilidad. Una cuestión es que las personas jurídicas necesiten siempre de personas físicas para actuar y otra, muy distinta, que recaiga sobre estas toda la responsabilidad de la empresa. Además, se puede sostener que este hecho irrefutable de que las personas jurídicas actúen siempre mediante personas físicas, no ha sido óbice para que estos entes colectivos asuman su responsabilidad en el Derecho Administrativo, en el Derecho Mercantil o en el Derecho Civil.

23. Llama la atención sobre este hecho: Gracia Martín, "Instrumentos de impucación jurídico penal en la criminalidad de empresa y reforma penal" en AP, 1993, p. 215. En la teoría general del Derecho se conoce este tipo de responsabilidad como responsabilidad indirecta o vicaria, cuando no coinciden el sujeto que realiza el acto ilícito y el sujeto de sanción. Cfr. Carlos Santiago Nino, Introducción al análisis del Derecho, Barcelona, Ariel, 1991, 4a edición, p. 187. En el Derecho Penal, en principio solo se admite la responsabilidad directa (principio de culpabilidad, responsabilidad personal), pero este principio admite excepciones, como son el caso de la responsabilidad de los representantes de sociedades y la autoría mediata.

En Derecho Penal se está imponiendo esta categoría a partir de la normativización de la responsabilidad penal. Esto es, se ha 1 legado al consenso, en las tesis funcionalistas, que la determinación de quién responde con una sanción penal, es una construcción socialvalorativa, un acuerdo intersubjetivo. Para HARDWIG, Die Zurechnung. Ein Zentralproblem des Strafrechts, ob. cit, p, 173, la cuestión central en materia de responsabilidad penal es determinar que un delito es realizado por una(s) determinada(s) persona(s). Según KORIATH, Grundlagen strafrechtlicher Zurechnung, Berlin, Duncker und Humboldt, 1993, p. 19, en el naturalismo, la imputación se fundamentó en la causalidad, en el finalismo se fundamentó en la estructura ontológica de la acción (final), y actualmente se fundamenta en la racionalidad del fin (Zweckrationalität), esto es, en la prevención del peligro o el riesgo de lesión para bienes jurídicos. 
que se produce una fragmentariedad en las decisiones y en la ejecución de las actividades delictuosas: los centros decisionales están fragmentados y el iter formativo de la voluntad parcializado. El concepto de delito abstraído a partir de consideraciones estáticas de la lesión de un bien jurídico por un sujeto, se aleja mucho de la nueva fenomenología dinámica de las conductas delictuosas que se producen en las actuaciones dentro de la empresa ${ }^{25}$. La complejidad de esta fragmentariedad de los procesos de toma de decisiones, formación de la voluntad y ejecución es mayor mientras más compleja sea la sociedad, pudiendo ir desde una empresa unipersonal a un consorcio de empresas o holdings, siendo creadas estas precisamente para diversificar riesgos y responsabilidades. En estos supuestos, el proceso de ejecución del delito suele ser el resultado de la confluencia de una pluralidad de actos parciales y fragmentarios de varios sujetos físicos, muchos de ellos cubiertos bajo el abrigo de corporaciones, en donde convergen una pluralidad de comportamientos dolosos y culposos, realizados por conductas activas u omisivas.

\section{Principales consecuencias en el ámbito penal de la existencia de esta nueva criminalidad.}

\subsection{Acentuación de los fines preventivos del Derecho Penal}

Como ya se ha puesto de manifiesto, el diagnóstico sociológico de "sociedad de riesgo" de nuestras sociedades pone el acento en la exigencia de convivir con riesgos irrenunciables como la empresa, la máquina o el automóvil, pero también con la necesidad de contenerlos, de limitarlos a lo legítimamente soportable (el riesgo permitido). La regulación de contención de riesgos, que normalmente se desarrolla con el Derecho administrativo sancionador, va a jugar un papel clave en la determinación de lo permitido y prohibido ${ }^{26}$, cuando se trata de bienes jurídicos colectivos o derechos sociales, propios de los delitos socioeconómicos. Se trata de la sinergia entre Derecho Penal y Derecho administrativo sancionador, donde varios tipos penales se configuran como "mero instrumento de cierre del sistema de control", y donde deslindar en la realidad injustos penales e injustos administrativos parece difícil, dada su extraordinaria similitud o, cuanto menos, su comunicabilidad: leyes penales en blanco, tipos abiertos, normas de reenvío, accesoriedad administrativa, técnicas de adelantamiento de la intervención, delitos de peligro abstracto, delitos

25 Cfr. PAliero, "L'autunno del Patriarca. Rinnovamento o trasmutazzione del diritro penal dei codici?, en RIDPP, 1994 , p. 1245.

26 Por ejemplo, la regulación de emisión permitida de contaminantes, respecto del delito contra el medio ambiente; la regulación del mercado bursátil respecto al delito de información privilegiada, etc. 
que sancionan la mera desobediencia, son todos aspectos de la nueva configuración de los modernos tipos penales.

Los efectos que tal caracterización de las modernas tipificaciones ha producido en el sistema dogmático penal, pueden concentrarse en la ya manida frase de "crisis del Derecho Penal". En efecto, además de la vulneración de principios por parte de esta moderna legislación, debe anotarse que en la propia doctrina ${ }^{27}$ también se han producido fisuras fundamentalmente por privilegiar en muchos casos la eficiencia, la estabilidad de la norma, la eficacia en la intervención ${ }^{28}$, sacrificando las categorías y sus reglas de imputación. Además de la garantía de taxatividad, quedan en entredicho los principios de ofensividad y culpabilidad, principales piedras de toque de la teoría del delito, así como las garantías de subsidiariedad y proporcionalidad en la intervención.

Este acento de los fines preventivos de la intervención penal y su consiguiente adelantamiento, tiene un significado para la cuestión de la responsabilidad penal de las personas jurídicas: dado que en el ámbito del Derecho Administrativo sancionador nadie discute la responsabilidad de las mismas, existiendo tal sinergia e interconexión con el Derecho Penal, necesariamente debe hacerse el replanteamiento del tema, por coherencia jurídica, y porque hoy en día el legislador responde indistintamente con uno u otro tipo de sanción.

\subsection{Preponderancia de bienes jurídicos colectivos}

La introducción en los códigos penales de los últimos decenios de delitos que protegen bienes jurídicos de carácter supraindividual como expresión del modelo del Estado social de Derecho, es una realidad indiscutible. Estos bienes jurídicos colectivos, supraindividuales o difusos crecen en la valoración social de los ciudadanos dada la trascendencia social y económica que su vulneración supone. Intereses tan importantes para la convivencia social de nuestras sociedades como el medio ambien-

27 En Alemania es conocida la polémica entre la Escuela de Hassemer y sus seguidores (Escuela de Franckfurt) que postulan una vuelta al "Derecho Penal clásico" y los demás autores, como SHUNEMANN, TIEDEMANN, Roxin, etc, quienes ven legítima la intervención penal en materia económica. En esta disputa ha sido fundamental la obra de KHULEN, "Zum Strafrecht derecho Risikogesellschaft", en GA, 1994. También puede señalarse la contribución de SHÜNEMANN, Consideraciones críticas sobre la situación espiritual de la ciencia juridico-penal alemana, trad. de Cancio Meliá, Bogotá, Universidad Externado de Colombia, 1996, pp. 15-42.

28 Se arguye una "natural" transformación de la intervención penal a las peculiaridades de la moderna criminalidad, una cierta "adaptabilidad" de los principios a las exigencias actuales de control de conductas. Cfr. SHÜNEMANN, Consideraciones críticas sobre la situación espiritual de la ciencia jurídico-penal alemana, ob. cit., p. 31: "el tránsito desde el delito de resultado clásico hacia el moderno delito de peligro abstracto prácticamente deriva de la naturaleza de las cosas". 
te, la Hacienda pública, la libre concurrencia, el mercado bursátil, los derechos de los trabajadores, la salud pública, la seguridad en el tránsito, para nombrar los más connotados, son tutelados actualmente por medio del Derecho Penal, el Derecho administrativo sancionador y por leyes especiales de carácter sancionatorio. Y, como otro factor desencadenante del aumento de intereses de carácter colectivo en la valoración de la ciudadanía y del legislador, es el reconocer la ingente cantidad de riesgos que asumimos por la convivencia con la técnica y que es menester controlar.

Es verdad que la consideración de los bienes jurídicos colectivos ha producido una expansión del Derecho Penal, pero esto no puede significar ni que sea ilegítima la intervención penal para tutelarlos, ni que la teoría del bien jurídico sea incapaz de constituir un límite al ius puniendi. Ambos extremos deben desecharse. Hoy pocos dudan en la necesidad de tutelar por medio del Derecho Penal bienes jurídicos de carácter colectivo $^{29}$, que se consideran fundamentales para el desarrollo social, como el medio ambiente, los derechos de los trabajadores, la libre concurrencia en el mercado, la salud pública y otros, dado que el modelo social del Estado en que vivimos, el aumento de riesgos para dichos bienes propio de las sociedades postindustriales, obligan al Estado a utilizar el recurso penal como gendarme mayor que garantice un umbral de legalidad mínimo en el despliegue de estos derecho fundamentales de tercera generación. Como sostiene Arroyo Zapatero ${ }^{30}$ : "Hoy la dañosidad social material de los delitos económicos se corresponde con la valoración moral negativa de los mismos por la Comunidad".

Por otro lado, estos bienes jurídicos colectivos que aquí nos ocupan son lesionados o puestos en peligro mayoritariamente en la realidad por empresas, sociedades, o entes colectivos en general. Incluso, como se ha dicho, algunos delitos que protegen bienes jurídicos colectivos solo pueden ser lesionados por empresas o corporaciones ${ }^{31}$, por ejemplo los delitos contra la libre concurrencia. Este hecho nos tiene que hacer reflexionar

29 No vamos a entrar en la discusión sobre la legitimidad de la tutela de bienes jurídicos, que compromete a todo el Derecho Penal económico. Es ciertamente minoritaria la tesis que considera que estos bienes no deben ser tutelados por el ordenamiento penal. De hecho, el propio legislador del 95 ha optado por la criminalización de los delitos socioeconómicos con claro afán de proteger bienes jurídicos colectivos. Aunque existe un sector minoritario de la doctrina alemana reacia a utilizar el recurso penal para estos bienes (Hassemer, Herzog), quienes reivindican la necesidad de una teoría monista-individualista del bien jurídico. Cfr. la situación espiritual en Alemania y las críticas a esta teoría en SHUNemanN, Consideraciones críticas sobre la situación espiritual de la ciencia juridico-penal, ob. cit., pp. 15 y ss,

30 En Arroyo/ Tiedemann, Estudios de Derecho penal económico, Cuenca, Univ. de CastillaLa Mancha, 1994, p. 16.

31 Cuando los arts. 372 y 303 CP dicen que los hechos pueden ser realizados por empresario, es evidente que el empresario asume la forma de persona jurídica, de sociedad, de empre- 
sobre los sujetos a los que se dirige la norma penal (Normadressaten) y, por tanto, en quienes se intenta motivar para que se cumpla la función preventiva de la misma. No hay que olvidar que la norma penal es un proceso comunicativo en el que los sujetos a los que se dirige juegan un rol fundamental.

\subsection{Superación del problema causal}

Como sostiene Shünemann, lo característico de la sociedad postindustrial actual consiste en el extraordinario incremento de las interconexiones causales ${ }^{32}$. Y ello se debe en gran medida a la producción industrial que es compleja, sectorializada, especializada, pluridimensional. $\mathrm{Si}$ a esto se une que las relaciones sociales se desarrollan mayoritariamente en contextos colectivos, donde se produce un distanciamiento de las relaciones personales y por tanto, entre agresor y víctima del delito, puede verificarse que los cursos causales sean múltiples, "cuyo esclarecimiento en detalle es de todo punto imposible con los métodos e instrumentos científico-naturales actuales a causa de su interrelación y de su compleja confluencia" 33 .

Efectivamente, la producción masiva de alimentos por parte de empresas alejadas de los consumidores, la distribución de los mismos mayoritariamente a través de grandes cadenas de almacenes, son una muestra de la ingente cantidad de cursos causales que pueden desarrollarse a los efectos de producir lesiones a la vida o a la salud de los consumidores. En el ámbito de los delitos contra el medio ambiente, donde también suelen intervenir sociedades o incluso empresas transnacionales, la prueba de la causación del daño también adquiere serias dificultades ${ }^{34}$.

La importancia de las teorías causales o de imputación objetiva, según su caso, adquieren relevancia pues son las encargadas de dilucidar

sa, Entonces en todos estos casos, el empresario (léase empresa, persona jurídica) es el sujeto acrivo de los delitos. Cfr, para el caso del art. 372 CuAdrado RUIZ, La responsabilidad por omisión de los deberes del empresario, Valencia, Tirant lo blanch, 1998, pp. 91 y ss. Cfr. para los delitos contra los trabajadores, Baylos / Terradillos, Derecho Penal del Trabajo, Madrid, Trotta, 1997, $2^{a}$ edición, p. 57 donde dice. "En el Derecho penal del trabajo el primer destinatario de la norma suele serlo el empresario, en cuanto que el ejercicio de su actividad lo coloca en la situación de garante directo, incluso exclusivo en ocasiones, de la salvaguarda de los bienes e intereses de los sujetos que forman parte de la estructura empresarial" (el subrayado es mío).

32 Vid. Shünemann, Consideraciones criticas sobre la situación espiritual de la ciencia jurídicopenal, ob. cit., p. 30.

33 SHÖNEMANN, Consideraciones críticas sobre la situación espiritual de la ciencia jurídico-penal, ob. cir., p. 31.

31 Cfr. KERNER, "Experiencias criminológicas con las recientes reformas para la lucha contra la criminalidad económica en la República Federal Alemana", en BARBERO SANTOS (ed.), La Reforma Penal: los delitos socioeconómicos, Universidad Complutense de Madrid, 1985, p. 158, quien sostiene que dicha prueba solo se ha conseguido en rarísimas ocasiones. 
si el riesgo para el bien jurídico se ha materializado en el resultado lesivo. No obstante, esta problemática que resultó central en los dos casos más sonados de responsabilidad por el producto defectuoso, como son el caso "Lederspray" y el caso "Colza", mostró que a pesar de los desarrollos doctrinales de la teoría de la imputación objetiva, subsisten serias limitaciones para demostrar si el riesgo desarrollado dentro del ámbito de una empresa se ha hecho efectivo en los daños a los consumidores ${ }^{35}$.

Los problemas para determinar si el riesgo producido dentro de una empresa, para bienes jurídicos como la salud pública o el medio ambiente, son los que efectivamente han causado las lesiones a los mismos, son hoy por hoy irresolubles bajo criterios ciertos de la teoría de la imputación objetiva o de la causalidad. El tema se complica aún más cuando intervienen una pluralidad de empresas, en las que hay una pluralidad de órganos o representantes.

\subsection{Dificultades para determinar a las víctimas y los resultados lesivos}

Este alejamiento entre sujeto agresor y víctima propio de los ilícitos que se cometen en organizaciones complejas y la concurrencia de una serie de procesos causales difícilmente determinables entre que se produce el riesgo y se desencadena el resultado, explican las dificultades para determinar a las propias víctimas y los resultados lesivos.

Las víctimas de muchos delitos socioeconómicos son indeterminadas, llegando a hablarse incluso de delitos sin víctimas. En muchos casos además los daños producidos a las mismas son heterogéneos, dependen de variantes vicisitudes, y se presentan en diferente tiempo y lugar ${ }^{36}$. El hecho que la mayoría de estos delitos vulneren bienes jurídicos colectivos también redunda en esta indeterminación, pues la tangibilidad de los mismos no es material, sino formal, jurídica. Más aún, para algunos autores, como Hassemer, los bienes jurídicos colectivos son indeterminados, difusos, intangibles, es decir sin existencia propia, sino solo funcionalizados en relación a la persona individual, por lo cual su lesividad también estaría funcionalizada de acuerdo a las personas.

En suma, la realidad criminológica moderna, organizada, transnacional, corporativa, socioeconómica, nos muestra que la mayoría de delitos son cometidos por entes colectivos complejos, jerarquizados, en los que

35 En términos similares HASSEmer / MUÑOz CONDE, La responsabilidad por el producto en Derecho Penal, Valencia, Tirant lo blanch, 1996, p. 51: "Ni siquiera las modernas teorías de la imputación objetiva, desarrolladas para solucionar los problemas de imputación que depara el tráfico automovilístico y la responsabilidad por imprudencia en general, han conseguido dar una fundamentación satisfactoria a la imputación de resultados, cuya producción no puede reconducirse inequívocamente a un determinado producto o a uno de sus componentes".

36 Es lo que sucedió en el caso de la Colza, lo cual incrementa el problema causal. 
predomina la división del trabajo, siendo en algunos casos solo cometidos por corporaciones. La protección efectiva de los bienes jurídicos colectivos de nuevo cuño, como el medio ambiente, la salud pública, los delitos contra los trabajadores, etc., cuya vulneración tiene gran trascendencia social y económica en los últimos tiempos, plantea nuevos retos a la dogmática penal fundamentada en la responsabilidad individual.

\section{LOS MODELOS DE RESPONSABILIDAD INDIVIDUAL: LA DECONS- TRUCCIÓN}

Las características anteriormente reseñadas de los delitos que se cometen en organizaciones complejas, en las que se produce una fragmentariedad en las decisiones y en la ejecución de las actividades delictuosas, esto es el tema de lo que Lampe denomina la responsabilidad penal en sistemas complejos ${ }^{37}$, chocan con la realidad de un sistema de imputación fundamentado en la responsabilidad de un sujeto individual, en el que la construcción teórica se ha inducido de un comportamiento estático centrado en el reproche a un individuo por no haber actuado de otro modo.

Desde los inicios de la construcción de la teoría del delito, el ílícito penal se fundamentó en una concepción individualista de sus fundamentos, injusto y culpabilidad. Así, el sistema dogmático que se fue diseñando ha tenido como base la responsabilidad personal. Para el causalismo naturalista, basado en concepciones mecanicistas, el eje de la responsabilidad penal era la vinculación natural del resultado a su autor. Incluso para los neoclásicos, lo esencial de la acción radica en la causalismo de un resultado procedente de la voluntad ${ }^{38}$. Esta concepción personal del delito llega a su más alta expresión, con la construcción de la acción final de Welzel en que se diseña un injusto personal como base de la teoría del delito $^{39}$. Los ejes, hasta hace muy poco, han sido el comportamiento humano voluntario (evitable) y la culpabilidad como un reproche perso-

Vid. más ampliamente LAMPE, "Systemunrecht und Unrechtssysteme", en ZSrW, 106, 1994, pp. 706 y ss.

Cfr. Jaen VAllejo, El concepto de acción en la dogmática penal, Madrid, Colex, 1994, pp. 31-33.

Cfr. Roxin, Derecho Penal. Parte General, La estructura de la teoría del delito, traducción y notas de D. M. Luzón Peña, M. Díaz y García Conlledo y J. De Vidente Remesal de la $2^{a}$ edición alemana, Madrid, Civitas, 1997, pp. 319 y ss.: “... la acción solo es antijurídica en cuanto obra de un determinado autor (...) La antijuricidad es siempre la desaprobación de un hecho referido a un determinado autor" (p, 320, el subrayado es mío). Cuando el problema es establecer ese "determinado autor" en sistemas complejos, el sistema penal no tiene otra respuesta que derivar el problema a otras ramas del ordenamiento jurídico. También Silva SÁnchez, "Introducción" en ShỨnemanN, El sistema moderno del Derecho Penal: cuestiones fundamentales, Madrid, Tecnos, 1991, p. 15, señala como uno de los puntos de consenso a los que llegado la doctrina dominante, el injusto personal integrado por el desvalor de acción y el desvalor de resultado. 
nal por no haber actuado de otro modo. A partir de esta concepción se construye todo el sistema dogmático centrado en un comportamiento personal de una persona física, la imputación subjetiva, la autoría y participación, la culpabilidad, etc., mostrándose también desde el punto de vista de la teoría del delito la imposibilidad de sancionar a las empresas con penas.

De esta manera, el modelo tradicional de respuesta frente al delito ha sido el de individualizar la responsabilidad penal. De ahí que la mayoría de países del sistema eurocontinental de tradición germánica hayan sido fieles al principio societas delinquere non potest. La legislación y la jurisprudencia han tenido que desarrollar dos modelos de individualización de responsabilidades, cuando los hechos son cometidos por personas jurídicas:

a) El modelo de la responsabilidad de los órganos y representantes.

b) El modelo de la responsabilidad del titular de la empresa.

En el primero la responsabilidad se centra en la base de la pirámide societaria, en el segundo se centra en el vértice de la misma. Finalmente es una decisión político-criminal de establecer dónde se considera que se infringen los mandatos de la norma penal, es un asunto de determinación de "la posición" del deber jurídico. Llámese la atención también, que en ambos casos se trata de "responsabilidades profesionales", es decir, adquiridas por asumir un cierto rol en la empresa, no por lo que en concreto se ha realizado ${ }^{40}$, cuestión que debe ser tenida en cuenta en la culpabilidad. La resolución del asunto, sin duda, adquiere dificultad. En palabras de Hassemer y Muñoz Conde: “ ¿cómo orientarse en la boscosa selva de los distintos niveles de decisión de una empresa en forma de sociedad mercantil, desde los más bajos peldaños de actuación hasta los más altos cargos directivos para decidir a quién o a quiénes y en qué grado corresponde atribuirle la responsabilidad penal por los daños producidos?" 41 . Decidir al respecto, dónde recae el deber de garante de los bienes jurídicos en juego, es una cuestión trascendente en los delitos cometidos en el ámbito de la empresa, que debe ser valorada en todas sus implicancias.

40 Cfr. Alessandri, "Parte General", en Pedrazzi / Alessandri / Foffani / Seminara / Spagnolo, Manuale de Diritto Penale dell impresa, Bologna, Monduzzi, 1998, p. 43.

41 Hassemer / MuÑoz Conde, La responsabilidad por el producto en Derecbo Penal, ob. cit., pp. 52 y 53 . 


\section{El modelo de la responsabilidad de los órganos y representantes}

También denominado responsabilidad hacia abajo ${ }^{12}$ porque concentra la responsabilidad en los representantes (normalmente legales, pero también de hecho), que suelen ser los escalones más bajos de la cadena funcional, quienes ejecutan las órdenes de un plan previamente concebido arriba. El principal escollo de este modelo de imputación es que no ataca la posible "actitud criminal de grupo", pudiendo ser los representantes fácilmente intercambiables, pues son sujetos fungibles ${ }^{43}$ dentro de la cadena funcional -meros ejecutantes, sino instrumentos de un plan ya concebido-, con lo cual no se consigue los efectos preventivo generales de la norma ${ }^{44}$.

El art. 31 del CP español y su antecedente el art. 14 del CP alemán, contienen una disposición de extensión de la responsabilidad al representante cuando este no posee los elementos especiales requeridos por el tipo penal en los delitos especiales, elementos que sí deben concurrir en la persona jurídica. Esta disposición permite superar mediante un criterio normativo, la escisión de los elementos del tipo legal en la realidad: el representante realiza el tipo, pero no tiene la capacidad para ser autor porque en estas normas el autor debe reunir ciertas características especiales, mientras que la persona jurídica es la que reúne dichas características, pero no puede realizar por sí misma el hecho típico. Sin esta disposición no podría penalizarse a estos representantes, pues estarían claramente fuera de la previsión legal. Así se introducen disposiciones específicas de extensión de la autoría formal de los delitos especiales a quienes actúan en lugar del sujeto cualificado ${ }^{45}$.

En primer lugar, tiene que individualizarse la responsabilidad de los directivos, representantes u órganos de la empresa y probar que realizan el tipo objetivo y subjetivo del delito. De lo contrario, estaríamos ante una presunción iuris et de iuri de culpabilidad o una regla de adscripción de responsabilidad, imposible de sostener con base en el principio de culpabilidad. Debe decirse que aunque en la teoría la concurrencia de

ACHENBACH, "Sanciones con las que se puede castigar a las empresas y a las personas que actúan en su nombre en el Derecho alemán", en SILVA SÁNCHEZ (Ed.), Fundamentos de un sistema europeo de Derecho Penal. Libro. Homenaje a Claus Roxin, Barcelona, Bosch, 1995, p. 382 .

43 Nótese que la empresa es una organización funcional, donde las personas juegan un rol funcional, lo importante son las funciones no las personas; estas pueden sucederse en el tiempo, siendo natural el recambio de personas físicas por meras cuestiones fisiológicas y se mantiene la continuidad de la organización. Cfr. Alessandri, "Parte General", ob. cit., p. 29.

44 Cfr. ShÜNEmann, "Cuestiones básicas de dogmática jurídico-penal y de política criminal acerca de la criminalidad de empresa", ob. cit., p. 533.

45 Gracia Martin, "Instrumentos de imputación jurídico-penal en la criminalidad de empresa y reforma penal", ob, cit., pp. 216-217. 
todos los elementos objetivos y subjetivos del tipo es un requisito de aplicación, en la praxis esto no sucede siempre así. Muchas veces se instruye al representante de la empresa por el hecho delictuoso que se atribuye a la persona jurídica, con lo cual prácticamente al representante se le adscribe la responsabilidad por el delito cometido dentro de la empresa sin comprobar siquiera si él conoce de la comisión del ilícito ${ }^{46}$.

El modelo de la responsabilidad de los órganos o representantes, acaba seleccionando a uno o varias personas físicas, órganos o representantes de la empresa como "chivos expiatorios", con el fin de no dejar el hecho impune y tranquilizar a las víctimas así como a la ciudadanía que reclama justicia ${ }^{47}$. Se trata de asegurar la responsabilidad civil ${ }^{48}$ para las víctimas y de reafirmar la prevención general positiva del delito. Esto, de alguna manera, es lo que ha sucedido con el capitán del Prestige, cuya detención y proceso penal apenas consumarse la catástrofe, siendo el único que hasta este momento ha respondido por ese complejo suceso, no es más que una puesta en escena, una función simbólica del Derecho penal.

El cuestionamiento más importante que se le hace a este modelo es que descarga la responsabilidad penal en sujetos con un limitado poder de decisión, quienes son en definitiva sustituibles, por lo que la "actitud criminal del grupo" o las conductas riesgosas para bienes jurídicos pueden mantenerse buscando otro representante.

\section{El modelo de responsabilidad del titular de la empresa}

Algunas legislaciones contemplan expresamente una disposición de infracción del deber de garante de los titulares de la empresa por los delitos y/o faltas que realicen sus subordinados. Así lo hace el art. 130 de la OWiG (Ley de Contravenciones) alemana y el art. 130 de la Ley de infracciones y sanciones administrativas española, Ley 30/1992, de 26 de noviembre. Ambas se encuentran en el ordenamiento administrativo sancionador y pueden considerarse sanciones punitivas, en sentido amplio ${ }^{49}$.

46 La jurisprudencia hasta hace muy poco consideró que los hechos punibles que se realizaban en el seno de una persona jurídica, eran autores del mismo, sea cual fuere la clase de delito que se comete (especial o no), las personas físicas que ejercen cargos de responsabilidad en la empresa. Vid. GRACIA MARTIN, "Instrumentos de imputación jurídico-penal en la criminalidad de empresa y reforma penal", ob. cit., p. 217 y la jurisprudencia que allí se cita.

47 Cfr. RODRÍGuez Ramos, “'Societas delinquere potest! Nuevos aspectos dogmáticos y procesales de la cuestión", en La Ley, 1996, p. 131.

48 El CP contempla que las personas jurídicas pueden responder civilmente: art. 117 (de las empresas aseguradoras), art. 120.2 a 5 (disposición general), art. 212 (solidaria en delitos contra el honor), todas del CP.

49 Cada vez es más clara la tendencia a considerar las sanciones administrativas como de carácter punitivo y, por tanto, sujecas a los principios del Derecho Penal. Esta conceptua- 
El CP de 1995 no contempla ninguna norma similar en la Parte General, pero sí existe la previsión general de la comisión por omisión del art. 11 que puede ser aplicada a todos los delitos cometidos en el seno de empresas, siempre que se cumplan con los requisitos allí estableci$\operatorname{dos}^{50}$. La interpretación más acertada de esta fórmula apuesta por una complementación entre fuentes formales y fuentes materiales de la posición de garante, por lo que las exigencias de concurrencia de un deber jurídico y la equivalencia de la conducta omisiva con la conducta activa según el texto de la ley, debe entenderse que, en estos casos se integra la situación típica del deber de actuar con la posición de garante que se presenta cuando corresponde al sujeto una específica función de protección del bien jurídico o una función personal de control de una fuente de peligro $^{51}$. La cuestión fundamental seguirá siendo cuándo hay una verdadera equivalencia material, cuestión que solo puede establecerse considerando la posición de garante, esto es la especial relación del sujeto con los bienes jurídicos ${ }^{52}$.

Es interesante analizar este modelo porque pese a no existir una disposición específica de responsabilidad por omisión del titular de la empresa por los delitos cometidos por sus subordinados (en el CP, pero sí en la Ley de Infracciones Administrativas, art. 130), la doctrina viene proponiendo la fundamentación de la responsabilidad de los directivos de las personas jurídicas a través de su posición de garante ${ }^{53}$. La jurispru-

lización de unificación del sistema sancionador ha sido acogida también por la jurisprudencia española en STC 18/1987, donde claramente se afirma "el ius puniendi del Estado se puede manifestar tanto en el ordenamiento penal como en el ordenamiento administrativo". Los alcances de esta aseveración para la responsabilidad penal de las personas jurídicas todavía está siendo evaluada por la doctrina, pues al existir ya la responsabilidad administrariva de las mismas, pretender aplicarles los principios de imputación subjetivos del Derecho Penal, da lugar necesariamente al replanteamiento del tema 0 , de lo contrario, se tendrá que asumir una responsabilidad objetiva en estos casos.

Los criterios de la comisión por omisión se suelen aplicar también para individualizar responsabilidades en el seno de órganos colegiados. Vid. PÉREZ CEPEDA, La responsabilidad de los Administradores de Sociedades: criterios de atribución, Barcelona, Cedecs, 1997, p. 65 y ss. Para los delitos contra la salud pública Vid. CUADRADO RUIZ, La responsabilidad por omisión de los deberes del empresario. Análisis crítico del art. 363 del CP, ob. cit., pp. 83 y ss. Cfr. en este sentido Mir PUIG, Derecho Penal. Parte General, ob. cit., p. 306 y MORALes PRATS, "art. 11 del CP", en Comentarios al CP, ob. cit, p. 90.

52 Como dice Serrano Piedecasas, "Crítica formal del concepto de omisión", en ADP. $C P, 1993$, p. 1001, la omisión jurídico-penalmente relevante consiste en un juicio de desvalor normativo sustentado en deberes extrapenales. Debe notarse también, que el sistema de control de la actividad económica, en donde el Derecho Penal viene a ser "el brazo armado", es un sistema basado en una red de obligaciones, poderes, funciones, donde la consideración de la forma omisiva para imputar responsabilidades concuerda rápidamente.

53 Cfr. Silva SÁNCHeZ, "La responsabilidad penal de las empresas y de sus órganos en el Derecho español" en Fundamentos de un sistema europeo del Derecho Penal, ob. cit., p. 378. LUSCARAIN, "Fundamento y límites del deber de garantía del empresario", en Libro Homenaje a Tiedemann, Madrid, Edersa, 1995, p. 210 y ss.; PÉREZ CEPEDA, La responsabilidad 
dencia también ha sancionado a los directivos de empresas cuando se produjeron lesiones a bienes jurídicos por la comercialización de productos defectuosos en los casos Colza y Leder Spray. Los Tribunales sancionaron a los directivos por un delito en comisión por omisión, infringiendo el deber de vigilancia respecto de las actividades de sus subordinados ${ }^{54}$.

Su fundamento consiste en que cuando varias personas trabajan coordinadas para conseguir un único objetivo, cada uno de los sujetos es no solo responsable de ejercer con corrección su actividad, sino también de controlar que dicha corrección se dé también en los restantes miembros de la cadena funcional. Todas las personas relacionadas con la fabricación o venta de un producto adquieren por ese hecho una posición de garante que les obliga a evitar el riesgo de que el producto pueda provocar daños a los consumidores. El Director o el responsable máximo del programa funcional, lo será también de todo el programa de actuación. Como puede observarse, en estos casos, contrariamente al modelo de imputación del representante, la responsabilidad se traslada al vértice de la estructura asociacional. Es por eso que también se le denomina responsabilidad hacia arriba.

Por su parte, el deber de vigilancia se funda en la función y el derecho de mando de los directivos de las empresas: relación de trabajo fáctica y limitada en el espacio por el empresario en las relaciones de autoridad, las cuales encuentran su apoyo en el contrato de trabajo, el derecho de dirección jurídico-laboral y la confianza de la Comunidad en el desempeño de sus funciones ${ }^{55}$.

El fin político-criminal de la responsabilidad del titular de la empresa (o de sus directivos) es muy interesante: instar a los gerentes, directores y demás responsables de la empresa para que desplieguen todas las labores exigibles de cuidado con el objeto de evitar que se produzcan delitos o contravenciones por sus propios subordinados.

Sin embargo, el gran cuestionamiento que se le hace a este modelo es que no existe acuerdo en determinar quiénes y con qué límites tienen posición de garante de las actividades de terceros en la empresa. Este es un tema central, porque está claro que responder por las actividades de terceros debe fundamentarse en una clara infracción de un deber nítida-

de Los Administradores de Sociedades: criterios de atribución, ob. cit., pp. 65 y ss; CUADRADO RuIz, La responsabilidad por omisión de los deberes del empresario. Análisis crítico del art, 363 del CP, ob. cit., pp. 83 y ss,

54 Cfr. HASSEMER / MuÑoz CONDE, La responsabilidad por el producto en derecho penal, ob.cit., pp. 98 y ss.

55 Cfr. BOTTKE, "Responsabilidad por la no evitación de hechos punibles de subordinados en la empresa económica, en Responsabilidad penal de las empresas y sus órganos y responsabilidad por el producto, ob. cit,, p. 133. 
mente determinado y que su incumplimiento, como decíamos, sea generador de riesgos para bienes jurídicos.

La incorporación de una regla específica en el CP de infracción del deber de vigilancia como la que tienen en Alemania, no soluciona, ni mucho menos, los problemas de imputación de los delitos que se cometen en el seno de una empresa porque: 1) Se asienta sobre bases dogmáticas poco consensuadas, cuales son los criterios de imputación de la omisión impropia. 2) Se corre el riesgo de "flexibilizar" los conceptos de la omisión para resolver supuestos complejos en los que el peso está en la salvaguarda del deber jurídico, convirtiendo la norma penal en un mero "delito de infracción del deber" (Pflichtdelikte) extra-penal. 3) No existe consenso en la doctrina penal en dónde recae la posición de garante, en el titular, en los directivos, en los administradores, en los asesores, etc., por lo que imputar responsabilidad en este campo puede conculcar el principio de culpabilidad que tanto se pretende salvaguardar. 4) Siguen quedando lagunas de punibilidad importantes ${ }^{56}$.

En suma, el modelo de la responsabilidad individual, al pretender individualizar la responsabilidad, ya sea en los eslabones más bajos de la cadena funcional (responsabilidad de los órganos o representantes) o en los directivos (responsabilidad del titular de la empresa) deja intactos los comportamientos organizacionales que suponen una política general del grupo y plantea serias lagunas de punibilidad al requerir siempre un sujeto que actúe con conciencia y voluntad o con infracción del deber de cuidado.

\section{LA RESPONSABILIDAD PENAL DE LA PROPIA PERSONA JURÍdica. PRINCIPALES PROBLEMAS}

Los países del Common Law y varios países próximos a nuestro sistema jurídico ${ }^{57}$, adoptan la punibilidad de las propias personas jurídicas.

56 Obsérvese que el art. 130 OwiG ha sido duramente criticado por la doctrina alemana. Vid. FRISCH, "Problemas fundamentales de la responsabilidad penal de los órganos de dirección de la empresa. Responsabilidad penal en el ámbito de la responsabilidad de la empresa y de la división del trabaja", ob. cit., pp. 122-127; RogALL, "Dogmatsiche und kriminalposlitische Probleme der Aufsichtspflichtverletzung in Betrieben und Unternehmen (\& 130 OwiG)" en ZStW, 1986, especialmente pp. 585 y ss. En la práctica esta norma funciona como "tipo de recogida" de los delitos cometidos en la actuación dentro de una empresa, cuando los instrumentos penales teóricos (impuración dolosa, culposa y autoría y participación) han fracasado. Dadas las dificultades para establecer el hecho de conexión y las personas cuya actuación vincula a la empresa, se ha propuesto que funcione en conexión con la multa asociacional del art. 30 OwiG, Cfr. TiedemanN, "Die Bebussung von Unternehmen nach dem 2. Gesetz zur Bekämpfung der Wirtschaftskriminalität", ob. cit.,, p. 1173. Establecer como hecho de conexión una contravención que necesita otro hecho de conexión, cual es el parágrafo $30 \mathrm{OwiG}$, puede ser un adelantamiento de la intervención intolerable, por lo menos en el ámbito penal. 
Asimismo, la UE desde sus tratados fundacionales se irroga la potestad de sancionar a empresas en materia de libre competencia, sanciones que se han reconocido tienen carácter punitivo ${ }^{58}$. Además, el Corpus Iuri ${ }^{59}$ incorpora una disposición en la que se reconoce la responsabilidad penal de las asociaciones de personas, estableciendo un criterio funcional para la persona que compromete con su actuación a la empresa o asociación. Asimismo, las legislaciones penales especiales y el Derecho administrativo sancionador sancionan directamente a empresas en muchos países ${ }^{60}$, sin haber planteado ningún inconveniente dogmático. $\mathrm{O}$, de lo contrario, como sucede con el CP español y otros que han seguido su impronta (como el peruano), establecen consecuencias accesorias para las personas jurídicas cuando se cometan delitos en su seno.

Vamos a analizar los dos campos en los que se ha reconocido sin ambages la aplicación de sanciones a las personas jurídicas:

\section{La responsabilidad de las personas jurídicas en el sistema san- cionador administrativo}

Como ya se ha tenido ocasión de expresar, en el campo del Derecho Económico existe una sinergia entre el recurso penal y el recurso administrativo. De hecho, el traspase de una rama del ordenamiento jurídico a otra es usual y no plantea problemas. La dificultad de este traspase se centra precisamente en el tema de la responsabilidad penal de las personas jurídicas, puesto que existe la contradicción en nuestro ordenamiento jurídico de empresas que pueden ser sancionadas administrativamente por infracciones menores y, cuando son más graves, no cabe responsabilidad penal para las mismas ${ }^{61}$. Es en este punto donde cabe reflexionar sobre el escollo más importante para asimilar las responsabilidades, que no es otro que el principio de culpabilidad para las personas jurídicas.

A propósito el Tribunal Constitucional se ha pronunciado en la STC 246/1991, en su fundamento jurídico 2: "Al respecto debemos recordar

Aunque se discure sobre su naturaleza jurídica, las sanciones comunitarias al tener carácter aflictivo (verdadera afección o limitación patrimonial o restrictiva de derechos patrimoniales) y preventivo (tiene un fin preventivo, buscar que no se vuelva a cometer la infracción), puede clasificarse como punitivas lato sensu. Vid. más ampliamente ZúNigA RODRfGUEZ, Bases para un modelo de imputación de responsabilidad penal a las personas jurídicas, ob. cit., pp. 147-150. Hay que reconocer que la jurisprudencia generada por la aplicación de estas sanciones está sirviendo de modelo para la construcción de un sistema de imputación a la propia persona jurídica.

59 Vid. Delmas-Marty / Vervaele (Eds.), The implementation of the Corpus Juris in the Member States, Vol. I, II, III y IV, Intersentia, 2002, 2001.

60 Esto sucede en Italia y Portugal especialmente, donde la legislación especial en materia de ilícitos económicos es copiosa y en ella se sanciona a empresas. Lo mismo ocurre en países de América Latina.

6i Es el caso de delitos tributarios que tienen una cuantía mínima. 
ahora que si bien es cierto que este TC ha declarado reiteradamente que los principios inspiradores del orden penal son de aplicación, con ciertos matices, al Derecho administrativo sancionador, dado que ambos son manifestación del ordenamiento punitivo del Estado (STC 18/1987 por todas), no lo es menos que también hemos aludido a la cautela con la que conviene operar cuando de trasladar garantías constitucionales extraídas del orden penal al derecho administrativo sancionador se trata. Esta operación no puede hacerse de forma automática, porque la aplicación de dichas garantías al procedimiento administrativo solo es posible en la medida que resulten compatibles con su naturaleza (STC 22/ 1990)". Prosigue la STC 256/1991: “... Este principio de culpabilidad rige también en materia de infracciones administrativas, pues en la medida en que dicha infracción es una de las manifestaciones del ius puniendi del Estado, resulta inadmisible en nuestro ordenamiento un régimen de responsabilidad objetiva o sin culpa (STC 76/1990)... Todo ello, sin embargo, no impide que nuestro Derecho administrativo admita la responsabilidad directa de las personas jurídicas y se haya suprimido el elemento subjetivo de la culpa, sino simplemente que ese principio se ha de aplicar necesariamente de forma distinta a como se hace respecto de las personas físicas. Esta construcción distinta de la imputabilidad de la autoría de la autoría de la infracción a la persona jurídica nace de la propia naturaleza de ficción jurídica a la que responden estos sujetos. Falta en ellos el elemento volitivo en sentido estricto, pero no la capacidad de infringir las normas a las que están sometidos. Capacidad de infracción y, por ende, reprochabilidad directa que deriva del bien jurídico protegido por la norma que se infringe y la necesidad de que dicha protección sea realmente eficaz"62. Esta sentencia, sin duda, sienta las bases de una responsabilidad directa de las personas jurídicas, delineando criterios subjetivos de imputación a partir del bien jurídico protegido y de la capacidad infractora de los sujetos a que se dirige la norma ${ }^{63}$.

El tema de fondo es que en el Ordenamiento Administrativo sancionador nos vemos ante la disyuntiva de sancionar a las personas jurídicas por la mera infracción (responsabilidad objetiva), o tendremos que delinear elementos de imputación subjetiva (dolo o culpa, y culpabilidad) para sancionarla, es decir, trasladar las construcciones de esta categoría del Derecho Penal. Como no es posible la primera alternativa, esto es, sancionar soslayando la garantía de que, por lo menos la persona jurídica habrá realizado la infracción imprudentemente, porque con ello se le

62 Fundamento jurídico $\mathrm{N}^{\circ}$ 2. Vid. comentarios de NiETo MaRTín, Fraudes comunitarios (Derecho Penal Europeo), Barcelona, Praxis, 1996, pp. 205-209. También Lozano, "La responsabilidad de la persona jurídica en el ámbito sancionador administrativo (a propósito de la STC 246/1991)", en RAP, $N^{\circ} 129,1992$, especialmente pp. 115 y ss.

63 Los alcances concretos de estos postulados se verán más adelante. 
estaría conculcando derechos fundamentales vinculados a la tutela judicial efectiva ${ }^{64}$, necesariamente tendrá que darse la segunda alternativa, esto es, pensar en criterios de imputación subjetivos para los entes colectivos, que en estos momentos representan los agentes económicos y sociales fundamentales de la Sociedad.

\section{Las consecuencias accesorias}

En realidad, la incorporación en el CP de 1995 de "consecuencias accesorias" aplicables a las personas jurídicas, supone que el legislador ha soslayado una discusión de fondo sobre la responsabilidad penal de las personas jurídicas, estableciendo una serie de medidas aplicables a las mismas, sin regular bajo qué criterios se imponen ni cómo. Esto es, acogiendo una demanda de necesidad de responder ante la creciente criminalidad que se efectúa bajo el manto de las personas jurídicas, el legislador dispuso una serie de consecuencias, dejando de lado las reglas de aplicación, problema al cual ahora nos enfrentamos crudamente. Para no comprometerse dogmáticamente, utilizó el término de "consecuencias accesorias", creyendo con ello obviar la discusión de fondo.

Hay que reconocer que la introducción en la Parte General de unas medidas para las personas jurídicas, junto con el decomiso de las ganancias obtenidas ilícitamente (arts. 104 y $105 \mathrm{CP}$ ) responde a una tendencia actual dentro de la política criminal moderna que, incidiendo en los fines preventivos de la pena, pone énfasis en el tipo de sanciones a aplicar, sin reflexionar detenidamente sobre el supuesto de hecho desencadenante de dicha consecuencia jurídica ${ }^{65}$. Bajo esta tendencia, el desarrollo de sanciones no personales, de tipo patrimonial ha sido espectacular, especial-

64 La titularidad de derechos fundamentales por parte de personas jurídicas es un tema también hoy discutido en el Derecho Constitucional. La CE no ha contemplado ninguna disposición al respecto, pero el TC ha reconocido, en relación a ciertos derechos fundamentales vinculados a la tutela judicial efectiva, la titularidad de las personas jurídicas. Cfr. Figueruelo, El derecho a la tutela judicial efectiva, Madrid, Tecnos, 1990, p. 62: "...la plena efectividad de los derechos fundamentales exige reconocer que la tirularidad de estos no corresponde solo a los individuos aisladamente considerados, sino también en cuanto se insertan en grupos y organizaciones. De este modo se reconoce la titularidad de los derechos fundamentales a la persona jurídica de derecho privado (art. 18.2 CE). Cfr. sentencia del TC $137 / 1985$, de 17 de octubre".

65 Tal cambio de perspectiva se debe a las demandas actuales político-criminales de satisfacer y reparar los intereses de la víctima, mientras que hasta ahora la pena se había centrado en sus efectos preventivo-generales para el autor y la Sociedad. Cfr. DÖLLING, "Die Weitwerentwiclung der Sanktionen ohne Freiheitsetzung", en ZStw, 1994, p. 265. En otros ámbitos delicrivos rambién se observa esta tendencia, que demuestra el desencanto de los fines resocializadores y el aumento de la sensibilidad de la opinión pública por el riesgo y la seguridad. Cfr. Silva SÁNCHEZ, "El retorno de la inocuización. El caso de las reacciones jurídico-penales frente a los delincuentes sexuales violentos", AA. Vv., Homenaje al Dr. Marino Barbero Santos. In memoriam, Vol. I, Univ. Castilla La Mancha I Univ. de Salamanca, Cuenca, 2001, p. 701, Más adelante este autor señala (p. 707): "El 
mente después de los atentados del 11 de septiembre de $2001^{66}$. Ello va en congruencia, también, con el auge de la criminalidad de grupo, especialmente la criminalidad organizada y de tipo empresarial, vinculadas al lucro ilícito, a las que se intenta hacer frente con medidas de embargo de su patrimonio ${ }^{67}$, con el objeto de estrangularlas económicamente y así impedir u obstaculizar el ciclo económico de las actividades ilícitas.

Creo que no es conveniente centrarse en la discusión sobre la naturaleza jurídica de las mismas, sino más bien establecer los presupuestos para su aplicación. En realidad, dado que se trata de medidas aplicables a las propias personas jurídicas por un juez penal, dentro de un proceso penal, por la comisión de delitos (hechos punibles), y tenemos un sistema penal basado en la responsabilidad personal, nos enfrentamos ante una serie de problemas que es importante dilucidar para lograr una cierta seguridad jurídica, necesaria si se quiere alcanzar los efectos preventivos invocados por la norma.

Considero importante, al menos, llegar al consenso sobre los siguientes temas:

1. ¿A qué personas jurídicas se pueden aplicar?

2. ¿Cuál es el supuesto de hecho que da lugar a la imposición de una consecuencia jurídica: la responsabilidad individual de una persona o de la propia persona jurídica?

3. ¿Qué principios rigen el proceso de imposición de las consecuencias accesorias?

4. ¿Cómo se ejecutan estas consecuencias accesorias?

Para esclarecer dichas cuestiones debe abordarse los alcances de los fines que el legislador pretende lograr con dichas medidas, esto es, qué objetivos pretende cumplir dentro del sistema de penas del ordenamiento penal. Un Derecho Penal orientado por el fin (Zweckrationalität), solo puede encontrar respuesta a las cuestiones fundamentales de sus instrumentos penales indagando qué objetivos político-criminales persigue con

debate acerca de las consecuencias jurídicas específicas de la sociedad de la inseguridad no ha hecho, probablemente, más que empezar".

Destacan en este ámbito las medidas adoptadas en la lucha contra el terrorismo internacional, por la Comisión europea (Documento 501PC0596), la cual ha propuesto una serie de medidas para enfrentarlo, atajando la financiación de las organizaciones terroristas, sin que existan criterios claros de atribución de responsabilidad, que previamente sirvan para determinar cuándo estamos ante una organización terrorista, con clara merma de la seguridad jurídica y del derecho de asociaciones.

67 Cfr. Vervaele. "Las sanciones de confiscación: ¿Un intruso en el Derecho Penal?, Revista Penal, n. 2, 1998, p. 67, quien pone de manifiesto la tendencia de las normas internacionales y especialmente europeas, orientadas a perseguir el patrimonio criminal, mediante el embargo y la confiscación, con clara influencia del modelo norteamericano, configurándose esta última como sanción independiente. 
ellos. En suma, el fundamento de las consecuencias accesorias se halla en sus fines, en lo que con ellas se pretende alcanzar.

Esta mención de ley ha dado pie a entender como fundamento de las mismas, el fin de prevención especial perseguido con estas medidas. En efecto, hay acuerdo en la doctrina y en la jurisprudencia de entender que las medidas de intervención deben estar encaminadas a evitar la continuidad de la actividad delictiva y de sus efectos, por tanto, este fin debe ser expresado en la motivación de la sentencia, vinculando la medida al fin perseguido ${ }^{68}$. Sin embargo, cuando pretendemos desentrañar qué actividad delictiva se pretende prevenir, la de la persona jurídica o la de sus miembros, los acuerdos ya son mucho menores. Creo que este es un tema fundamental para establecer si el supuesto de hecho se refiere a la responsabilidad de la propia persona jurídica o de las personas que actúan bajo su amparo.

En la medida que la norma de determinación está vinculada no a la voluntariedad del comportamiento humano, sino a los destinatarios de la norma (Normadressaten), lo importante es a quién se pretende motivar con la misma. Es decir, a qué sujetos motivables se dirige la norma ${ }^{69}$. De hecho, la mayoría de delitos socioeconómicos se dirige a la contención de riesgos en el ámbito de empresas, como los delitos laborales, financieros, societarios, contra la libre competencia, etc. Incluso puede sostenerse que las empresas y otras asociaciones, por moverse en el mundo jurídico y económico, son sujetos enormemente motivables pues sus comportamientos se rigen por la reputación, la fama, en suma la fiabilidad de sus consumidores $^{70}$.

En todo caso, considero que debe distinguirse dos supuestos muy distintos ${ }^{71}$ desde el punto de vista teórico, aunque en la práctica muchas veces las fronteras se diluyen:

Cfr. por todos Prats Canut, en Quintero Olivares (dir), Comentarios al Código Penal, Pamplona, Aranzadi, 1996, pp. 627-628,

En sentido similar BACIGALUPO, La responsabilidad penal de las personas juridicas, Barcelona, Bosch, 1998, p. 368; ZuGALDía, La responsabilidad criminal de las presonas jurídicas en el derecho penal español (Requisitos sustantivos y procesales para la imposición de las penas previstas en el artículo 129 del Código Penal)", Quintero Olivares / Morales Prats (CoORds.), El nuevo Derecho Penal Español. Estudios Penales en Memoria del Profesor José Manuel Valle Muñiz, Aranzadi, Navarra 2001, p. 889.

70 De hecho los escándalos económicos de los últimos tiempos en los Estados Unidos, Casos Enron, Ercross, han dado lugar a una crisis de fiabilidad tal en los consumidores que ha rebertido en una caída de los mercados bursátiles. Incluso, se han tipificado nuevos delitos de control de entidades financieras para atajarlos. Ello prueba que las empresas se mueven por su repuración y que esta es fundamental para sus logros económicos.

Vid. más ampliamente ZUÑIGA RODRf́GUEZ, Bases para un modelo de imputación de responsabilidad penal a las personas juridicas, ob. cit., 2003, pp. 230-233. Siguiendo a LAMPE, "Systemunrecht und Unrechtsysteme", ob. cit., 1994, pp. 706-713, quien hace esta clasificación de injustos de sistemas complejos, aunque considera los dos supuestos enunciados más un tercero que sería el caso de las corporaciones criminales estatales 
1. La persona jurídica es un mero instrumento en manos de unos sujetos individuales que poseen fines criminales.

2. La persona jurídica posee fines lícitos, pero por un defecto de organización pone en peligro o lesiona bienes jurídicos importantes.

En el primer caso, la instrumentalidad de la persona jurídica es clara y se configura como un objeto peligroso en manos de unos sujetos que actúan dolosamente. Este actuar es propio de la criminalidad organizada que crea, mantiene, transforma y disuelve sociedades según le sea los fines ilícitos. En estos casos es de aplicación el tipo penal de asociaciones ilícitas del art. 515 CP. Nótese que en este supuesto está claro que finalidad de la norma es prevenir la continuidad de la propia asociación, en tanto organización que tiene como fines o medios la comisión de delitos $^{72}$.

Distinto es el supuesto en el que una persona aprovecha el contexto de una persona jurídica para cometer un delito o este se produce por un defecto de organización o por políticas de empresa que desbordan los riesgos para bienes jurídicos. En estos casos es más fácil ver que la persona jurídica no es un mero instrumento en manos de unos determinados sujetos, sino que se produce un injusto de organización, esto es, una lesión a bienes jurídicos fruto de un contexto de organización defectuo$\mathrm{sa}^{73}$. Ejemplo de estos serían los delitos por infracción de las normas de prevención de accidentes laborales, los delitos contables de los casos Enron o Ercross, etc. Parece claro que aquí sí estamos ante actividades de empresa que se pretenden prevenir (defecto de organización, omisión por los delitos cometidos por los subordinados, etc.).

El principal problema de las consecuencias accesorias del art. 129 es que parecen requerir previamente la imposición de una sanción a una persona individual ${ }^{74}$, lo cual daría lugar a una práctica inaplicabilidad de las mismas, puesto que precisamente individualizar responsabilidades, como se ha visto, es la principal dificultad. Como es lógico, esta inter-

(aparatos de poder organizados), a las que se les puede dar el mismo tratamiento que el de las asociaciones ilícitas, pero criminológicamente tienen algunas peculiaridades. A los efectos de la aplicación de las consecuencias accesorias que nos interesa, para las que claramente están fuera del supuesto de hecho las organizaciones estatales, nos basta con ambos supuestos.

72 Cfr. REAÑo Peschiera, Autoría y participación en delitos especiales de funcionarios públicos cometidos en el marco de organizaciones criminales: un análisis dogmático a partir del delito de asociación ilícita", SAN MARTín CASTRO / CARO CORIA / REAÑo PESCHIERA, Delitos de tráfico de influencias, enriquecimiento ilícito y asociación para delinquir. Aspectos sustantivos y procesales, Jurista, Lima, 2002, p. 300.

73. Sobre los problemas concretos de injusto, culpabilidad y penalidad, vid. más ampliamente ZÚNiga RODRigueZ, Bases para un modelo de imputación de responsabilidad penal a las personas jurídicas, ob. cit., pp. 227-245. Es lo que ha entendido la jurisprudencia y doctrina mayoritaria. 
pretación constriñe prácticamente la aplicación de las mismas, puesto que habrá que probar la responsabilidad penal de un autor para proceder a aplicarlas.

Sin embargo, la jurisprudencia última de suspensión de las actividades del partido político vasco, el Auto de 8 de octubre de 2002 de la Sala Penal de la Audiencia Nacional que confirma el auto de 26 de agosto de 2002 , parece admitir la tesis de una responsabilidad de la propia organización, independiente de la de sus miembros. El auto reconoce la tesis de que "bien puede ocurrir que durante la instrucción del proceso queden antes evidenciadas las actividades delictivas en el seno y en el objeto real de la organización, y una vez descubiertas, se puedan perfilar nítidamente los indicios racionales de criminalidad en personas individuales". Esto es, respecto a las vinculaciones entre responsabilidades individuales y responsabilidad de la organización, si bien lo normal es que la responsabilidad penal de sus miembros denoten la responsabilidad de la organización, no se puede desdeñar la posibilidad de que antes de comprobar la responsabilidad penal individual queden evidenciadas las actividades delictivas de grupo y en el objeto real de la organización.

Mientras no se resuelvan todos los extremos apuntados, el fin político-criminal preventivo de las consecuencias accesorias será prácticamente nulo.

\section{La construcción dentro del propio Derecho Penal o un modelo paralelo}

En realidad, dentro de las opciones posibles para imputar responsabilidad penal al propio ente, las dos soluciones fundamentales que se plantean $\operatorname{son}^{75}$ a) utilizar los mecanismos de imputación existentes en la dogmática penal, los cuales demostrarían una funcionalidad incluso para sancionar penalmente a las personas jurídicas; b) diseñar un sistema nuevo de imputación penal para el propio ente, construyendo categorías y principios especialmente elaborados a partir de las características de las organizaciones complejas.

75 Según Silvina BACigalupo, La responsabilidad penal de las personas juridicas, ob. cit., p. 359, las soluciones que pueden proponerse son: a) rebajar las exigencias el principio de culpabilidad; b) elaborar un sistema específico de responsabilidad penal de las personas jurídicas; y, c) desviar al ámbito del Derecho Administrativo o Civil. De acuerdo a esta propuesta, descartaría las opciones a) y c). La primera, porque ya se ha visto que es posible conciliar el principio de culpabilidad con la responsabilidad (penal o administrativa)de las personas jurídicas y, más bien, se ha insistido en la necesidad de equiparar principios -relativamente, en función del bien jurídico- en todo el orden sancionador, a partir del paradigma penal. La segunda, porque ya se ha puesto en evidencia que la prevención de la criminalidad, para los casos graves, debe estar siempre en manos del orden penal, ya sea que sea cometida por persona física o jurídica. 
Creo que la opción a) tiene estructuralmente sus límites teóricos. La flexibilización de las categorías de la omisión, la posición de garante, la imprudencia, la imputación objetivo para hacer responder a los directivos de empresas por casos de responsabilidad por el producto, puede tener un efecto perverso, contaminador de todo el sistema penal.

Concretamente, la teoría de la autoría y participación, ha sido diseñada a partir de la individualización de un sujeto (accesoriedad de la participación), que ha realizado el comportamiento con dolo. Prueba de ello es que a pesar de las transformaciones sufridas en los últimos tiempos, en que se ha pasado de categorías que valoraban la contribución causal al hecho para individualizar responsabilidades, a construcciones en las que la responsabilidad se fundamenta en la previsión de cuidado, muy próximas a la teoría de la imputación objetiva, todavía no existen consensos suficientes en la participación de los delitos imprudentes ${ }^{76}$ y los de omisión ${ }^{77}$, principales formas de conductas que ocurren en la criminalidad de empresa. La complejidad de sucesos que dan lugar a la realización de delitos en sistemas organizados, aunada a la falta de acuerdo de la doctrina sobre la responsabilidad en la autoría y la participación, principalmente en materia de participación imprudente en que es mayoritaria la tesis de la impunidad, nos plantean un panorama bastante desolador para la seguridad jurídica que debe presidir la intervención penal ${ }^{78}$ y grandes posibilidades de lagunas de punibilidad. De ahí que muchas veces, los denunciados problemas probatorios en estos casos, sean en realidad verdaderos problemas de deficiencias en los criterios de imputación.

La opción b) de creación de un modelo paralelo de responsabilidad a la propia persona jurídica, al lado del ya existente de responsabilidad, permite cerrar el círculo de la relación responsabilidad individual y responsabilidad de la organización ${ }^{79}$.

Abona en favor de la tesis que debe abordarse los fenómenos de delitos cometidos en sistemas complejos en clave de sistema, empresa u organización, el hecho constatado científicamente, de que los peligros y lesiones de bienes jurídicos dentro de una empresa, son la mayoría de las veces resultado de defectos de una serie de conductas atribuibles a la organización de la propia empresa (políticas de empresa), que no pueden

Incluso se plantea la impunidad de la participación en los delitos imprudentes de lege lata: Cfr. Luzón PeÑa, Curso de Derecho Penal. Parte General I., Madrid, 1996, p. 501; Pérez Manzano, Autoria y participación imprudente en el Código penal de 1995, Madrid, Civitas, 1999, pp. 109-110.

77 Vid. epígrafe precedente el modelo de la responsabilidad del titular de la empresa.

78 Como previene CARBONEL, Derecbo Penal, concepto y principios constitucionales, Valencia, Tirant lo blanch, 1996, 2a edición, el peligro de la dogmática de llegar a distintas soluciones según el sistema que se adopte, le despoja de su función básica de dotar de criterios seguros al juez.

Siguiendo a Lampe, Heine, Tiedemann y Baigún. 
individualizarse en una concreta decisión de una concreta persona, sino en una deficiencia de largos años de falta de cuidado del riesgo consciente $^{80}$. En efecto, estudios hechos por los norteamericanos sobre delitos en corporaciones (Corporate crime), han puesto de manifiesto que los mismos se producían por una serie de políticas de la propia empresa, mala organización, incumplimiento de normativas, falta de vigilancia, lo cual aunado a otros factores hacían que los riesgos aumentasen hasta desencadenar la lesión a bienes jurídicos ${ }^{81}$.

Los estudios sobre teoría de la organización, no solo ponen en evidencia los cambios en el comportamiento individual dentro del seno de organizaciones, sino también que puede hablarse de un comportamiento organizacional. Hoy en día se comprende a la organización como un sistema que influye en el comportamiento de los individuos, tratándose de un comportamiento organizacional ${ }^{82}$.

\section{Problemas de injusto y culpabilidad del modelo}

Veamos los principales problemas con que se topa un modelo de responsabilidad penal de la propia persona jurídica.

El primer escollo con el que una imputación penal al propio ente colectivo tropieza es el considerar que la propia persona jurídica es capaz de realizar una acción penalmente relevante, sino siempre son sujetos individuales los que actúan por las corporaciones. A esta postura, por cierto asentada prácticamente como un dogma en la doctrina ${ }^{83}$, cabe oponerle las siguientes objeciones:

Primero, desde concepciones ontológicas de la acción penal, fundadas en un injusto personal como infracción de la norma de determinación (entendida como voluntariedad), es imposible salir del círculo vicioso que supone el razonamiento tautológico siguiente: la acción penal es un comportamiento humano final (voluntariedad), por tanto las personas jurídi-

\footnotetext{
80 Cfr. Oтто, "Die Haftung für kriminelle Handlungen in Unternehmen", en Jura, 8, 1998, p. 416 .

81 Cfr. Wells, "Corporations: culture, risk and Criminal Liability", en The Criminal Law Review, 1993, pp. 558-567.

82 Cfr. Mouzelis, Organización y burocracia, ob, cit., p. 158. De ahí que sean importante los problemas de poder y de conflictos entre grupos.

83 Para la doctrina dominante y la manualística española las personas jurídicas no son capaces de realizar una acción penal. Cfr. por rodos GRACIA MARTín, "La responsabilidad penal de la propia persona jurídica,", en AP, 1993, pp. 603 y ss., las personas jurídicas no son sujetos capaces de acción penal porque no pueden ser objeto de la norma de determinación. También la mayoría de los manuales parten de la incapacidad de acción penal de las personas jurídicas para negar su responsabilidad penal Vid. por todos: BERDUgo / ARroyo / Garcia Rivas / FERRÉ Olivé / SERrano-Pidecasas, Lecciones de Derecho Penal Parte General, Barcelona, Praxis, 1996, p. 115.
} 
cas no son capaces de realizar una acción penal ${ }^{84}$. Es decir, partiendo del principio que solo las conductas de personas físicas son penalmente relevantes, no es posible, en ningún caso, replantear, de manera crítica, la posibilidad de que las sociedades delincan. De ahí que por este camino la discusión estaría en un "callejón sin salida", pese a que en la realidad constatáramos criminológicamente la incidencia de la criminalidad realizada por corporaciones.

Segundo, hoy en día las concepciones actuales no centran la discusión de la responsabilidad penal en el problema de la acción, pues este concepto ha resultado con poco rendimiento, para determinar qué es relevante penalmente ${ }^{85}$. A lo más, la teoría de la acción ha servido para establecer qué no es acción penalmente relevante, cumpliendo más bien una función negativa, de exclusión del injusto, como lo estableciera Beling ${ }^{86}$. Las posturas teleológico funcionalistas que hoy son dominantes, centran ese "punto de arranque" en el tipo de injusto como expresión valorativa de sentido, la cual está condicionada por los fines políticocriminales de la norma penal, esto es prevención y protección de bienes jurídicos. De manera que la determinación de lo jurídico-penalmente relevante es una valoración sustentada en esos paradigmas y que representan una dañosidad social grave evitable plasmada en la ley penal. La acción penal ha dejado de ser el "punto de arranque" de la imputación penal, porque hoy en día es sumamente compleja, intervienen una serie de factores naturalísticos, fortuitos, antropológicos, biológicos, psíquicos en el actuar humano, por lo que no podría establecerse un sustrato común que responda a la realidad fenomenológica de la criminalidad actual. Desde estos presupuestos, teniendo en cuenta que la realidad criminológica nos enseña que los ilícitos se realizan muchas veces en contextos colectivos, donde los intervinientes son sujetos colectivos y existe una complejidad de nexos causales, lo importante no es "la acción penalmente relevante", sino la dañosidad social evitable, el resultado que viene a ser

Recordemos que esta concepción responde al método finalista, según el cual el objeto de conocimiento determina el método $y$, por tanto, el comportamiento humano, que es el objeto, es el "sustrato fáctico". De cómo desde el ontologismo tampoco puede replantearse el problema de los elementos del dolo, vid., últimamente, LAURENZO, Dolo y conocimiento, Valencia, Tirant lo blanch, 1999, p. 105. Desde posturas ontologistas, HIRSCH, "La cuesrión de la responsabilidad penal de las asociaciones de personas", en ADPCP, 1993, p. 1106. para quien las acciones de sus órganos, son también acciones propias de las asociaciones, las que son destinatarias reales de los deberes jurídicos. Cfr. MARINUCCI, El delito como "acción, Crítica de un dogma, traducción de Saínz-Cantero Caparrós, Madrid, Marcial Pons, 1998, p. 14.

86 Cfr. MARINUCCI, El delito como "acción, Crítica de un dogma, ob. cit., p. 16; JAEN VAllejo, El concepto de acción en la dogmática penal, ob. cit., p. 93. 
la plasmación del riesgo desaprobado por el ordenamiento (suceso evitable que lesiona o pone en peligro bienes jurídicos importantes $)^{87}$.

En suma, si se entiende como modernamente suele entenderse el hecho penalmente relevante, como el comportamiento de sujetos destinatarios de la norma penal, a los que les llega el mandato de valoración y el mandato de determinación, esto es, que son motivables por dicha norma, no existe inconveniente en sostener que las personas jurídicas pueden ser sujetos activos de delitos o ser capaces de realizar una acción penal.

En realidad, el escollo dogmático más importante que existe para sancionar penalmente a las asociaciones y, por tanto, establecer como supuesto de hecho de las consecuencias accesorias la realización de una conducta de organización, es que se considera que de estas no se puede predicar el dolo o la culpa, elemento esencial de toda infracción penal. Es decir, las personas jurídicas carecerían de los elementos subjetivos para imputar una sanción en clave penal. Esta postura de imposibilidad conceptual de elementos subjetivos en la persona jurídica se basa en una concepción de los mismos a partir de la persona humana, concretamente a partir de la voluntad humana. A ello cabe responder con dos argumentos concretos. Primero, sí es posible concebir elementos subjetivos en empresas y organizaciones. No solo la práctica real de la imposición de sanciones a empresas por el Derecho de la Libre Competencia de la UE, sino también desde el punto de vista doctrinal se puede concebir una construcción de dolo o culpa de organización. El dolo, superando el elemento volitivo, puede conceptuarse como la conciencia del riesgo para los bienes jurídicos; y la culpa, se puede concebir como la ausencia de conciencia evitable del riesgo para bienes jurídicos ${ }^{88}$.

En lo que respecta a la culpabilidad, o las características que debe poseer el sujeto para que responsa penalmente, desde el momento en que la responsabilidad penal o la imputación personal de culpabilidad ya no es entendida como reprochabilidad por no haber actuado de otro modo (fundada en el libre albedrío), sino normativamente, desde el punto de vista social, puede dar respuestas satisfactorias al fenómeno de la delincuencia asociacional.

87 Concepción dominante, por otro lado, en la teoría de la imputación objetiva, cuya discusión ha ocupado buena parte de los últimos años, Vid. por todos, Roxin, La imputación objetiva en el Derecho Penal, traducción de Abanto Vásquez, Lima, Idemsa, 1997, pp. 109 y ss. Roxin, "Acerca de la consolidación político-criminal del sistema de Derecho Penal", en Roxin, Dogmática penal y Política Criminal, ob. cit., p. 27.

88 Siguiendo la teoría del Tribunal de Justicia de Comunidad Europea para los delitos contra la libre competencia se han desarrollado estos conceptos, teniendo en consideración la teoría cognitiva del dolo (Laurenzo, Dolo y conocimiento, ob. cit., pássim.), Vid. más ampliamente ZÚNIGA, Bases para un modelo de imputación de responsabilidad penal a las persanas juridicas, ob. cit., pp. 237-239. 
Si actualmente se considera que el contenido material de la culpabilidad está asociado a las funciones de la pena, esto es, prevención general y prevención especial, la atribución de responsabilidad penal es un problema de lineamientos de merecimiento y necesidad de pena por parte del legislador en base a capacidades para ser destinatarios de la norma penal. Las personas jurídicas son los principales destinatarios de las normas penales de los delitos socioeconómicos y no es posible desconocer su capacidad de motivación. Para una empresa, la fama, el buen nombre, el prestigio es muy importante para competir en el mercado, por lo que una sanción pública puede tener claros efectos preventivos.

\section{CONCLUSiONES: DE LA DECONSTRUCCIÓN A LA CONSTRUCCión DE UN MODELO DE RESPONSABILIDAD PENAL A LA PERSONA JU- RÍDICA}

El proceso de revisión del principio societas delinquere non potest que está sufriendo en los últimos tiempos no es más que una consecuencia del auge de una criminalidad organizada, empresarial, económica, transnacional que está demostrando un amplio poder criminógeno. Las vinculaciones entre criminalidad de empresa y criminalidad organizada encuentran como núcleo de interrelación a la empresa, como agente social en el que se encuentran el mundo del tráfico lícito e ilícito. Los escándalos financieros de los últimos tiempos, las organizaciones financieras que sirven de soporte al terrorismo, los desastres ecológicos, son todos delitos que se cometen en el seno de una organización empresarial, con vinculaciones con organizaciones ilícitas.

Las dificultades que conlleva la individualización de responsabilidades da lugar a serias lagunas de punibilidad. La deconstrucción o cuestionamiento de los modelos de responsabilidad individual ponen evidencia sus deficiencias, puesto que no solo no atacan la actitud criminal del grupo o los defectos de organización que ponen en riesgo los bienes jurídicos, sino que tampoco colman los efectos preventivos esperados por la norma penal dada su escasa aplicabilidad.

La construcción de un modelo de responsabilidad penal de la persona jurídica paralelo a la responsabilidad individual, permite distinguir cuando un ilícito es cometido por una persona física que se sirve de una persona jurídica y cuando se trata de un ilícito de organización, un tipo de criminalidad de grupo. Los estudios sobre teoría de la organización confirman la necesidad de indagar por este camino, pese a las dificultades aún existentes. Solo así podremos hacer frente con eficacia a la macrocriminalidad que demuestra su extraordinario poder criminógeno, sin soslayar garantías básicas de un Estado de Derecho. 
Las transformaciones que se están produciendo en el sistema de penas, en el que se incorporan sanciones no personales como la pena privativa de libertad, y la mayor valoración de los bienes jurídicos socioeconómicos, abonan en la dirección de reflexionar sobre nuevas soluciones para nuevos problemas.

\section{BIBLIOGRAFÍA CITADA}

- ACHENBACH, "Sanciones con las que se puede castigar a las empresas y a las personas que actúan en su nombre en el Derecho alemán", en SILVA SÁNCHEZ (ED.), Fundamentos de un sistema europeo de Derecho Penal. Libro Homenaje a Claus Roxin, Barcelona, Bosch, 1995.

- Alessandri, "Parte General", en Pedrazzi / Alessandri / Foffani / Seminara / Spagnolo, Manuale de Diritto Penale dell 'impresa, Bologna, Monduzzi.

- Antón Oneca, Derecho Penal, anotado y corregido por J. Hernández y B. Merino, Madrid, Akal, 1986, $2^{a}$ edición.

- Arroyo /Tiedemann, Estudios de Derecho penal económico, Cuenca, Univ. de Castilla-La Mancha, 1994.

- Bacigalupo, La responsabilidad penal de las personas jurídicas, Barcelona, Bosch, 1998.

- Baylos / Terradillos, Derecho Penal del Trabajo, Madrid, Trotta, 1997, 2a Edición.

- Berdugo / Arroyo / García Rivas / Ferré Olivé / SerranoPidecasas, Lecciones de Derecho Penal Parte General, Barcelona, Praxis, 1996.

- Carbonel, Derecho Penal, concepto y principios constitucionales, Valencia, Tirant lo blanch, 1996, $2^{\text {a }}$ Edición.

- Cerezo Mir, Curso de Derecho Penal Español, Introducción I, Madrid, Tecnos, 1996.

- Cid Moliné, "Garantías y sanciones (argumentos contra la tesis de la identidad de garantías entre las sanciones punitivas)"

- Cuadrado Ruiz, La responsabilidad por omisión de los deberes del empresario, Valencia, Tirant lo blanch, 1998.

- De Castro y Bravo, Persona jurídica.

- Delmas-Marty / Vervaele (EDS.), The implementation of the Corpus Juris in the Member States, Vol. I, II, III y IV, Intersentia, 2002, 2001.

- Diario El País, 8 de noviembre de 2002.

- Döll.ing, "Die Weitwerentwiclung der Sanktionen ohne Freiheitsetzung", en ZStw, 1994.

- Figueruelo, El derecho a la tutela judicial efectiva, Madrid, Tecnos, 1990. 
- García ARÁN, "Remisiones normativas, leyes penales en blanco y estructura de la norma penal", en EPC, $\mathrm{N}^{\circ}$ XVI, 1993.

- García de Enterría, Curso de Derecho Administrativo, Madrid, Civitas, 1984 , T. II, $2^{a}$ edición

- Gracia Martín, "Instrumentos de imputación jurídico penal en la criminalidad de empresa y reforma penal" en AP, 1993.

- Gracia Martín, "La responsabilidad penal de la propia persona jurídica.”, en AP, 1993.

- HARDWIg, Die Zurechnung. Ein Zentralproblem des Strafrechts.

- Hassemer / MUÑOz CONDE, La responsabilidad por el producto en Derecho Penal, Valencia, Tirant lo blanch, 1996.

- Hirsch, "La cuestión de la responsabilidad penal de las asociaciones de personas", en ADPCP, 1993.

- Jaen VAllejo, El concepto de acción en la dogmática penal, Madrid, Colex, 1994.

- KALDOR, Las nuevas guerras. La violencia organizada en la era global, traducción de M.L. Rodríguez Tapia, Barcelona, Tusquets, 1991.

- Kerner, "Experiencias criminológicas con las recientes reformas para la lucha contra la criminalidad económica en la República Federal Alemana", en BArbero SAnTos (ED.), La Reforma Penal; los delitos socioeconómicos, Universidad Complutense de Madrid, 1985.

- KORIATH, Grundlagen strafrechtlicher Zurechnung, Berlin, Duncker und Humboldt, 1993.

- KHULEN, "Zum Strafrecht derecho Risikogesellschaft", en GA, 1994.

- LAMPE, "Systemunrecht und Unrechtssysteme", en ZSrW, 106, 1994.

- Laurenzo, Dolo y conocimiento, Valencia, Tirant lo blanch, 1999.

- LozANo, "La responsabilidad de la persona jurídica en el ámbito sancionador administrativo (a propósito de la STC 246/1991)", en RAP, $N^{\circ} 129,1992$.

- Luscarain, "Fundamento y límites del deber de garantía del empresario", en Libro Homenaje a Tiedemann, Madrid, Edersa, 1995.

- Luzón Peña, Curso de Derecho Penal. Parte General I., Madrid, 1996.

- Marinucci, El delito como "acción, Crítica de un dogma, traducción de Saínz-Cantero Caparrós, Madrid, Marcial Pons, 1998.

- Martínez PÉrez, "La inflación del Derecho Penal y del Derecho Administrativo", en EPC, N ${ }^{\circ}$ VI, 1983.

- MAYNTZ, Sociología de la organización, Madrid, Alianza Universidad, $1990,5^{a}$ reimpresión.

- Mouzelis, Organización y burocracia. Un análisis de las teorias modernas sobre organizaciones sociales, Barcelona, Ediciones Península, 1991, $3^{\text {a }}$ edición.

- Nieto Martín, Fraudes comunitarios (Derecho Penal Europeo), Barcelona, Praxis, 1996. 
- Nino, Carlos S.: Introducción al análisis del Derecho, Barcelona, Ariel, 1991, 4a edición.

- Отто, "Die Haftung für kriminelle Handlungen in Unternehmen", en Jura, 8, 1998

- PALIERo, "L'autunno del Patriarca. Rinnovamento o trasmutazzione del diritto penal dei codici?, en RIDPP, 1994.

- PARAda VÁsquez, "Las sanciones administrativas", en AA. VV., La empresa en la CE, Madrid, Ed. Aranzadi, 1989.

- Pérez Cepeda, La responsabilidad de los Administradores de Sociedades: criterios de atribución, Barcelona, Cedecs, 1997.

- PÉrez MANZANo, Autoría y participación imprudente en el Código penal de 1995, Madrid, Civitas, 1999

- Polaino Navarrete, "Derecho Penal criminal y Derecho administrativo sancionador", en RCLM, N ${ }^{\circ} 7,1989$.

- Prats Canut, en Quintero Olivares (Dir), Comentarios al Código Penal, Pamplona, Aranzadi, 1996.

- RAmONET, Guerras del siglo XXI. Nuevos miedos, nuevas amenazas, traducción de J. A. Soriano, Barcelona, Mondadori, 2002.

- REAÑo PESChiera, "Autoría y participación en delitos especiales de funcionarios públicos cometidos en el marco de organiząciones criminales: un análisis dogmático a partir del delito de asociación ilícita".

- Rodríguez Ramos, "iSocietas delinquere potest! Nuevos aspectos dogmáticos y procesales de la cuestión", en La Ley, 1996.

- Rogall, "Dogmatsiche und kriminalposlitische Probleme der Aufsichtspflichtverletzung in Betrieben und Unternehmen (\& 130 OwiG)" en ZStW, 1986.

- Roxin, Derecho Penal. Parte General, La estructura de la teoría del delito, traducción y notas de D.M. Luzón Peña, M. Díaz y García Conlledo y J. De Vidente Remesal de la $2^{\mathrm{a}}$ edición alemana, Madrid, Civitas, 1997.

- Roxin, La imputación objetiva en el Derecho Penal, traducción de Abanto Vásquez, Lima, Idemsa, 1997.

- San Martín Castro / Caro Coria / Reaño Peschiera, Delitos de tráfico de influencias, enriquecimiento ilícito y asociación para delinquir. Aspectos sustantivos y procesales, Jurista, Lima, 2002.

- Serrano Piedecasas, "Crítica formal del concepto de omisión", en ADPCP, 1993.

- SHÜNEMANN, Unternebmenskriminalität und Strafrecht, Köln- BerlinBonn/München, Carl Herymanns Verlag, 1979.

- ShÚnemanN, "Cuestiones básicas de dogmática jurídico-penal y de política criminal acerca de la criminalidad de empresa", en ADPCP, 1988

- Shünemann, Consideraciones críticas sobre la situación espiritual de la ciencia jurídico-penal alemana, trad. de Cancio Meliá, Bogotá, Universidad Externado de Colombia, 1996. 
- Silva SÁnchez, La expansión del Derecho Penal. Aspectos de la Política Criminal en las sociedades postindustrializadas, Madrid, Civitas, 2001, $2^{a}$ edición,

- Silva SánChez, "Introducción" en ShünemanN, El sistema moderno del Derecho Penal: cuestiones fundamentales, Madrid, Tecnos, 1991.

- Silva SÁNCHEZ, "El retorno de la inocuización. El caso de las reacciones jurídico-penales frente a los delincuentes sexuales violentos", AA. Vv., Homenaje al Dr. Marino Barbero Santos. In memoriam, Vol. 1, Univ. Castilla La Mancha / Univ, de Salamanca, Cuenca, 2001.

- SuAY Rincón, Sanciones Administrativas, Bolonia, Publicaciones del Real Colegio de España

- Terradillos, "Delitos societarios y grupos de empresas", en Baylos / Collado (eds.), Grupos de Empresas y Derecho del Trabajo, Madrid, Trotta, 1994.

- Torío, "Injusto penal e injusto administrativo (presupuestos para la reforma del sistema penal)", en Estudios sobre la CE en Homenaje a García de Enterría, Madrid, Civitas, 1991, T III.

- Vervaele,. "Las sanciones de confiscación: ¿Un intruso en el Derecho Penal?, Revista Penal, n. 2, 1998.

- Wells, "Corporations: culture, risk and Criminal Liability", en The Criminal Law Review, 1993.

- Zugaldía, La responsabilidad criminal de las presonas jurídicas en el derecho penal español (Requisitos sustantivos y procesales para la imposición de las penas previstas en el artículo 129 del Código Penal)", en Quintero Olivares / Morales Prats (CoOrds.), El nuevo Derecho Penal Español. Estudios Penales en Memoria del Profesor José Manuel Valle Muñiz, Aranzadi, Navarra 2001.

- Zúñiga Rodríguez, Política Criminal, Madrid, Colex, 2001.

- ZÚNiga RodrígueZ, "Relaciones entre Derecho Penal y Derecho administrativo sancionador ¿Hacia una 'administrativización' del Derecho Penal o una 'penalización' del Derecho administrativo sancionador?, en AA. Vv., Homenaje al Dr. Marino Barbero Santos, In memoriam, Cuenca, Ediciones de la Universidad de Castilla- La Mancha / Universidad de Salamanca, 2001.

- ZÚNIgA RodrígueZ, Bases para un modelo de imputación de responsabilidad penal a las personas jurídicas, Pamplona, Aranzadi, 2003, $2^{\mathrm{a}}$ edición. 